\title{
Guía operativa para programas de educación sexual y servicios de salud reproductiva para jóvenes
}

Ofelia Aguilar

Lorena Santos

Marisa Diaz Infante

Rocio Mejia

Ricardo Vernon

See next page for additional authors

Follow this and additional works at: https://knowledgecommons.popcouncil.org/departments_sbsr-rh

Part of the Demography, Population, and Ecology Commons, and the International Public Health Commons

How does access to this work benefit you? Let us know!

\section{Recommended Citation}

Aguilar, Ofelia, Lorena Santos, Marisa Diaz Infante, Rocio Mejia, Ricardo Vernon, and Antonieta Martin. 2008. "Guía operativa para programas de educación sexual y servicios de salud reproductiva para jóvenes." Mexico, D.F.: Population Council/FRONTERAS y MEXFAM. 


\section{Authors}

Ofelia Aguilar, Lorena Santos, Marisa Diaz Infante, Rocio Mejia, Ricardo Vernon, and Antonieta Martin 


\section{Guía operativa para progra mas de educación sexual y senvicios de salud reproductiva para jóvenes}
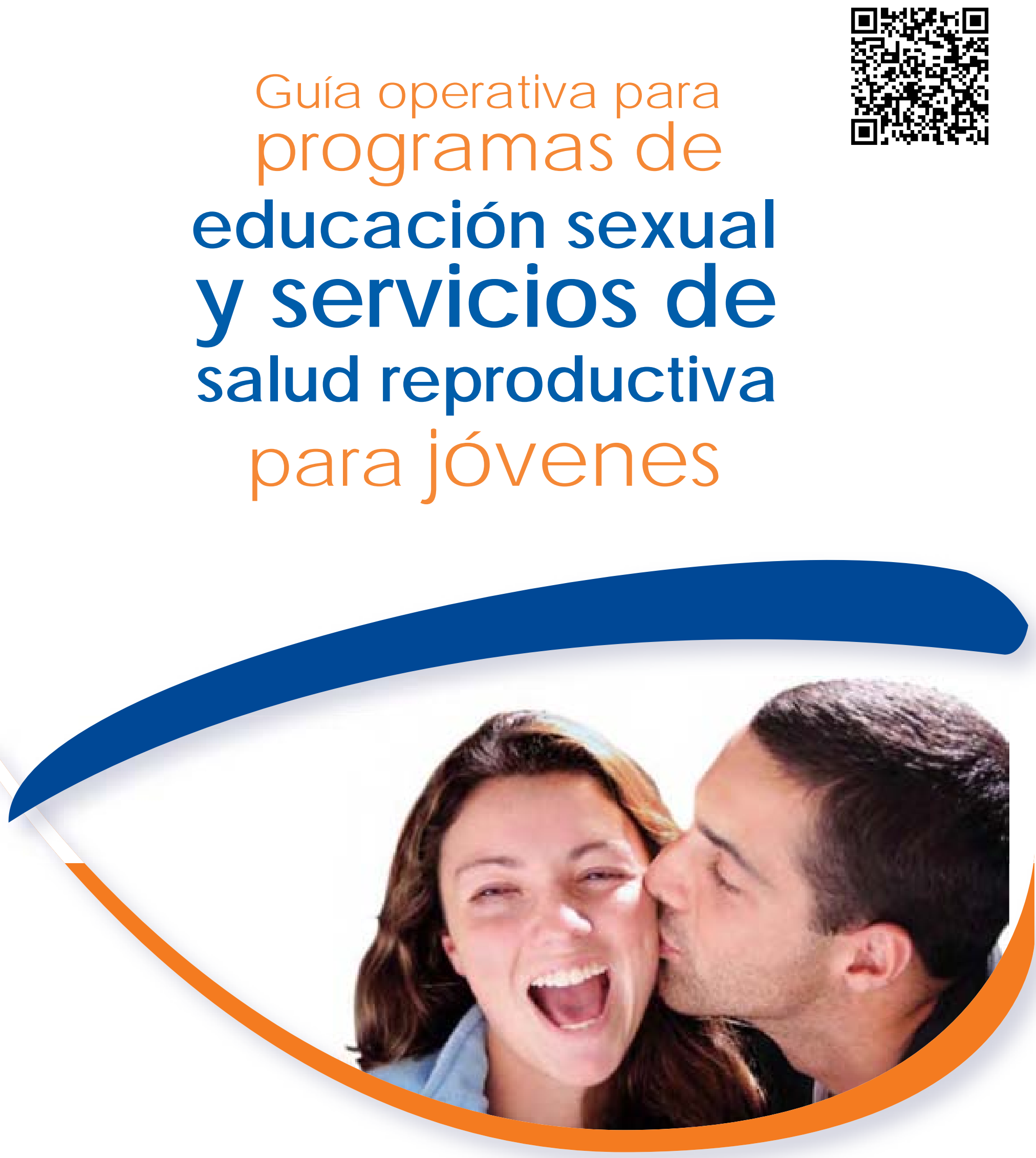

(1) Population Council FRONTERAS
Mexfam

Salud para tu familia 


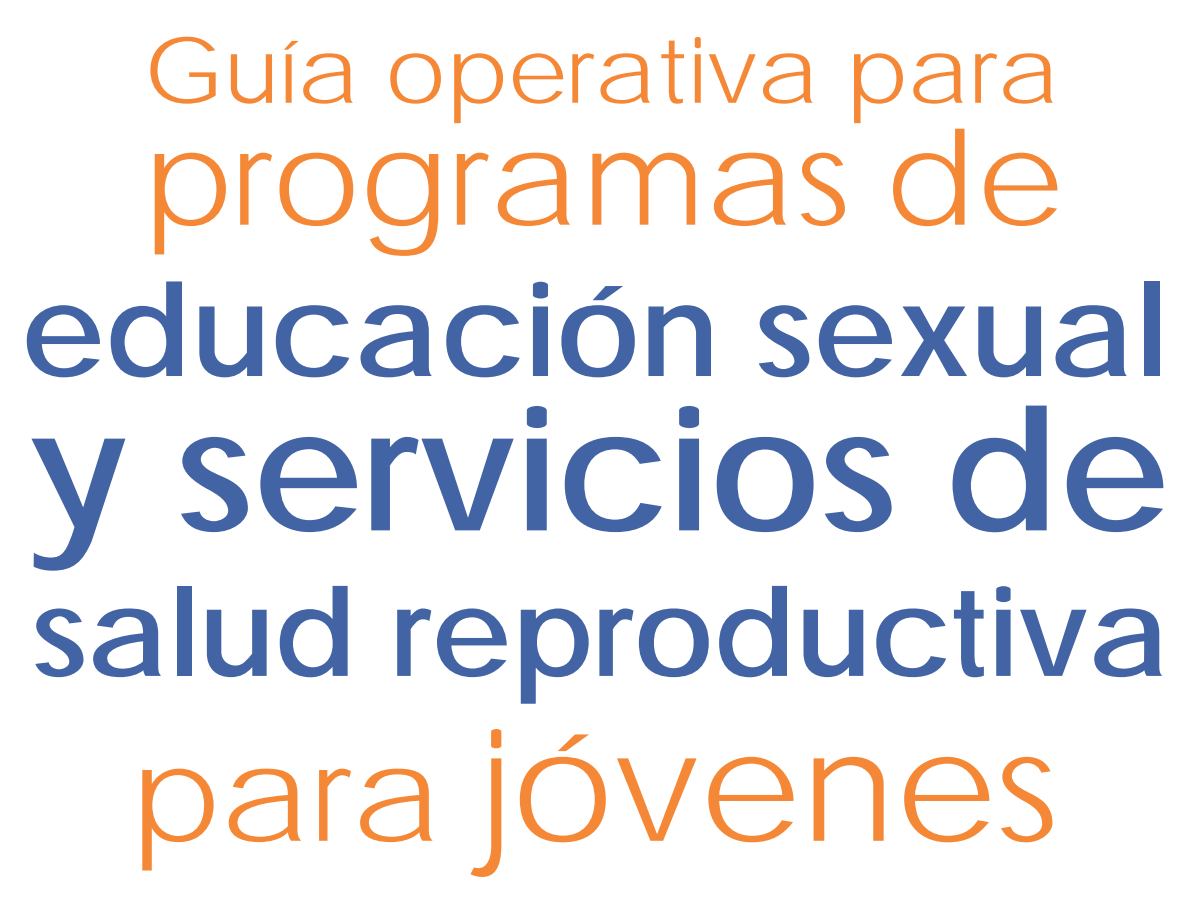


Aguilar, Ofelia, Lorena Santos, Marisa Díaz Infante, Rocío Mejía, Ricardo Vernon y Antonieta Martín. 2008. "Guía operativa para programas de educación sexual y servicios de salud reproductiva para jóvenes." México, D.F.: Population Council/ FRONTERAS y MEXFAM.

El Population Council es una organización internacional, no lucrativa y no gubernamental, que busca mejorar el bienestar y la salud reproductiva de las generaciones presentes y futuras del mundo y ayudar a alcanzar un equilibrio humano, equitativo y sostenible entre la población y los recursos. El Council realiza investigación biomédica, en ciencias sociales y salud pública, y ayuda a fortalecer la capacidad de investigación en países en desarrollo. El Council fue fundado en 1952 y está dirigido por un consejo directivo internacional. Su oficina matriz en Nueva York apoya a una red mundial de oficinas regionales y nacionales.

\section{Population Council}

One Dag Hammarskjold Plaza

New York, N.Y. 10017

\section{E.U.A.}

Tel. (212) 339-0500

\author{
Population Council \\ Escondida 110, Col. Villa Coyoacán \\ 04000 México, D.F. \\ MÉXICO
}

Tel (52-55) 5999-8630

www.popcouncil.org

El Programa Fronteras de la Salud Reproductiva (FRONTERAS) aplica sistemáticamente técnicas de investigación para mejorar la prestación de servicios de planificación familiar y salud reproductiva y para incidir en las políticas relativas a estos servicios. El Programa FRONTERAS es financiado por la Agencia para el Desarrollo Internacional de Estados Unidos (USAID) y es dirigido por el Population Council en colaboración con Family Health International.

\section{Population Council/FRONTERAS}

4301 Connecticut Ave., N.W. Suite 280

Washington, D.C. 20008

www.popcouncil.org/frontiers

(C) Population Council, Inc

Esta publicación se realizó con el generoso apoyo del pueblo estadounidense a través de la Agencia de los Estados Unidos para el Desarrollo Internacional (USAID), bajo los términos del Acuerdo de Cooperación No. HRN-A-00-98-00012-00, y de las Fundaciones Gates y Packard. Los contenidos son responsabilidad del Programa FRONTERAS y de MEXFAM y no necesariamente reflejan los puntos de vista de USAID, del Gobierno de los Estados Unidos o de las fundaciones.

Cualquier parte de esta publicación podrá reproducirse sin autorización de los editores, siempre y cuando cite la fuente y se utilice sin fines comerciales.

Edición: Angélica Aguirre

Diseño gráfico y editorial: David Arias

Primera edición: 2008

ISBN: 978-968-6373-39-4

D.R. Fundación Mexicana para la Planeación Familiar, A.C. 


\section{Índice}

I. Introducción 5

II. Objetivos del Programa Gente Joven 8

$\begin{array}{ll}\text { III. Población beneficiaria } & 11\end{array}$

IV. Diagnóstico e implementación, paso a paso 14

1. Solicitud de apoyo 15

2. Formación del equipo básico 15

3. Trazo de mapas y croquis 15

4. Visitas domiciliarias y registro 16

$\begin{array}{ll}\text { 5. Elaboración de encuesta } & 18\end{array}$

6. Preparación de bases de datos 19

$\begin{array}{ll}\text { 7. Búsqueda de financiamiento } & 19\end{array}$

8. Programación de actividades $\quad 19$

9. Establecimiento de metas 20

V. Componentes del Programa juvenil 21

$\begin{array}{ll}\text { Componente comunitario } & 23\end{array}$

Componente escolar $\quad 43$

Componente de servicios $\quad 49$

Médicos amigables $\quad 49$

Farmacias amigas $\quad 53$

VI. El coordinador y los promotores juveniles 57

$\begin{array}{ll}\text { Coordinador juvenil } & 58\end{array}$

Perfil del coordinador juvenil $\quad 58$

Selección del coordinador juvenil 58

Funciones del coordinador juvenil $\quad 59$

$\begin{array}{ll}\text { Sus retos } & 62\end{array}$ 
Promotores juveniles

Selección de los promotores juveniles

Actividades de los promotores juveniles

Educación entre pares: la receta secreta

Misión del voluntario

VII. Capacitación

Momentos de la capacitación

Características de las actividades de capacitación

¿Quién imparte los cursos?

¿Qué capacitación adquirir?

El abc de la capacitación

Taller de sexualidad (es) Bienestar

Taller de sexualidad (es) para la gente joven

Sesión de comunicación familiar

Taller de vida erótica y protegida

Atención Integral del Adolescente (AIDA)

Taller sobre Infecciones de Transmisión Sexual, VIH y SIDA

Taller sobre orientación-consejería

Diplomado en sexualidad humana

VIII. Recursos del Programa

Recursos materiales

Recursos financieros 


\section{INTRODUCCIÓN}


El presente libro tiene como fin poner al alcance de personas y organizaciones interesadas en establecer políticas y programas de servicios y educación sexual para los jóvenes, una guía basada en el Programa Gente Joven que implementa la Fundación Mexicana para la Planeación Familiar, A.C. (MEXFAM).

Consideramos que los componentes y las actividades de este programa pueden ser adaptados en otras latitudes y así enriquecer proyectos orientados al trabajo con jóvenes.

\section{Un acercamiento al Programa Gente Joven}

El Programa Gente Joven pretende promover entre los jóvenes aquellos valores vinculados con la salud sexual, como la responsabilidad reproductiva, la comunicación y el amor entre las personas. Trabaja en zonas marginadas a través de centros de servicio juvenil, centros de salud, organizaciones juveniles y otras instituciones del sector público que atienden a jóvenes, como los centros de integración juvenil y consejos tutelares. Cuenta además con un espacio de referencia, de y para los jóvenes, donde se llevan a cabo actividades diversas dirigidas a la educación sexual.

La operación del Programa se realiza por medio de tres componentes:

1. Comunitario, que opera en todos los lugares donde haya jóvenes, incluyendo la calle y centros de trabajo.

2. Escolar, en el que participan alumnos y maestros de escuelas de nivel secundaria y preparatoria.

3. De servicios, que opera en las clínicas de MEXFAM, centros de salud, hospitales públicos, consultorios médicos privados y farmacias.

\section{Sus protagonistas}

Los recursos humanos con los que opera el Programa Gente Joven son, primordialmente:

Gerente de MEXFAM. Responsable de la marcha en general del Programa, y de actividades clínicas y de promoción en una zona geográfica determinada que se conoce como "área logística".

Coordinador Gente Joven. Se encarga directamente de organizar y supervisar el Programa en una localidad determinada.

Promotores juveniles voluntarios. Son el motor del Programa y realizan la mayor parte de las actividades en la comunidad, en las instituciones de salud, en las farmacias y en las escuelas. 
Comité Gente Joven. Integrado por los promotores juveniles más experimentados y dinámicos, quienes apoyan al Coordinador Gente Joven en la organización de las actividades.

Voluntarios adultos. Además de los jóvenes que fungen como promotores juveniles voluntarios, el Programa también busca la participación activa de voluntarios adultos, especialmente los maestros en las escuelas, que son capacitados por MEXFAM y que a su vez instruyen a sus estudiantes; médicos y paramédicos del sector público y del sector privado, a los que también se capacita para que presten servicios apropiados o amigables a los jóvenes, así como farmaceutas, quienes han demostrado ser un importante apoyo para la difusión de la salud reproductiva y el acceso a los métodos anticonceptivos.

En las siguientes secciones ampliaremos la información sobre todos estos componentes y recursos, explicaremos la forma de implementación del Programa y describiremos los diferentes tipos de capacitación que se imparten.

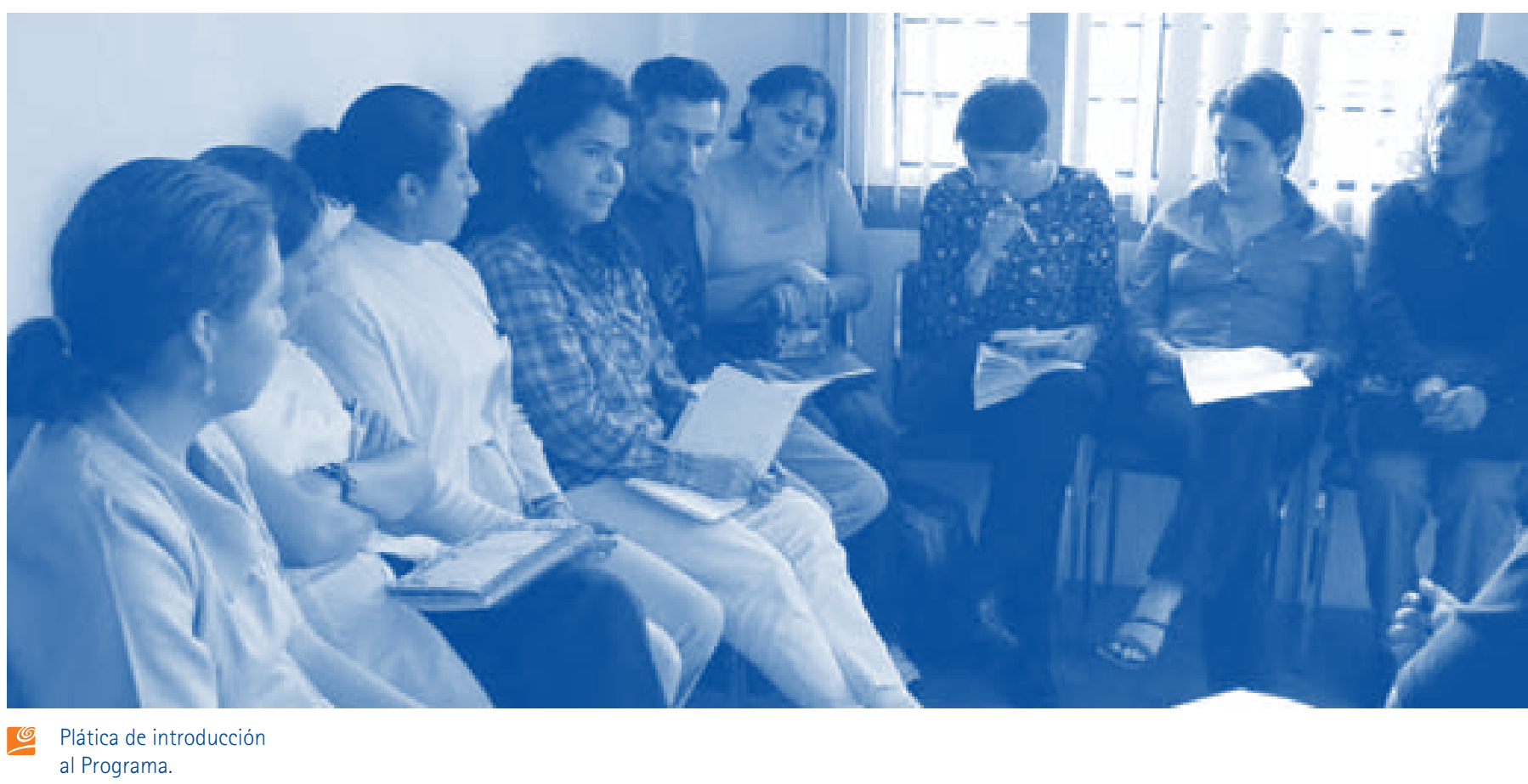




$$
\begin{array}{r}
\text { I. OBJETIVOS DEL } \\
\text { PROGRAMA GENTE } \\
\text { JOVEN }
\end{array}
$$


Gente Joven, que desde 1986 ha implementado estrategias de educación sexual, es un programa dedicado a la población de ambos sexos de entre 10 y 24 años de edad. En 1994 adoptó un enfoque de derechos sexuales y reproductivos para responder a las necesidades de información y servicios de salud sexual y reproductiva de los jóvenes de México.

\section{Objetivo general}

Promover una nueva cultura de salud sexual basada en los derechos humanos, en el ejercicio libre, informado y placentero de las sexualidades, en la convivencia y diálogo de las diversidades, en el aprecio entre las personas y en la creatividad resultante de todo ello, así como garantizar el acceso a servicios incluyentes de salud sexual y reproductiva con calidad y calidez.

\section{Objetivos específicos}

- Lograr que un número cada vez mayor de jóvenes reciba oportunamente la información y los servicios médicos que requieran para tomar decisiones que garanticen su salud sexual, la prevención de embarazos no deseados o no planeados, y la protección contra las infecciones de transmisión sexual (ITS), especialmente del Virus de Inmunodeficiencia Humana (VIH) y del Síndrome de Inmunodeficiencia Adquirida (SIDA).

- Promover la comunicación familiar entre los jóvenes y sus padres, proporcionando la orientación sobre sexualidad que ambos necesiten.

- Difundir valores de respeto, responsabilidad reproductiva y equidad de género entre jóvenes y adolescentes, y el convencimiento de posponer los embarazos hasta una etapa de la vida en la que puedan hacer frente al compromiso de ser padres y madres.

- Desarrollar actitudes positivas hacia la salud sexual juvenil en las comunidades en donde se implementa el Programa.

- Promover la existencia de servicios amigables de salud sexual juvenil.

- Proporcionar capacitación en sexualidad al personal docente y de salud responsable de atender a jóvenes.

- Garantizar la participación de los jóvenes en los procesos de toma de decisiones, en el diseño de políticas y de programas juveniles. 


\section{\|l.. POBLACIÓN BENEFICIARIA}




\section{¿Con quién trabaja el Programa?}

El Programa da cabida a una amplia variedad de beneficiarios. Prácticamente atiende a cualquier joven interesado en obtener información y orientación para manejar su sexualidad y planear su vida. Entre ellos están:

- habitantes de comunidades marginadas rurales o urbanas;

- jóvenes que no estudian ni trabajan, estudiantes, empleados, en busca de empleo o desempleados;

- miembros de bandas, de clubes o de otras organizaciones;

- asiduos visitantes de centros deportivos o de recreación.

Además de trabajar directamente con los jóvenes, el Programa también lo hace con adultos que pueden influir en ellos, especialmente con:

- Docentes de todos los niveles escolares, especialmente a partir de 50 año de primaria, que requieren ser capacitados en sexualidad juvenil y orientación-consejería sobre temas de salud sexual y reproductiva.

- Madres y padres de familia interesados en capacitarse para orientar a sus hijos y a otros jóvenes en temas relativos a su desarrollo, a la sexualidad y a la prevención de ITS, incluyendo VIH/SIDA, y embarazos no planeados o no deseados.

- Médicos, paramédicos y psicólogos que proporcionan servicios de salud sexual y reproductiva a gente joven.

- Farmaceutas interesados en atender a los jóvenes de manera amigable, dándoles información y orientación en salud sexual y reproductiva cuando acuden a las farmacias a obtener condones, anticoncepción de emergencia o cualquier método que les permita prevenir embarazos e ITS/VIH/SIDA.

\section{¿Dónde se implementa?}

Las actividades que el Programa realiza están localizadas en áreas geográficas definidas y seleccionadas de acuerdo a dos criterios principales: concentración de población joven y altos índices de necesidades no satisfechas. Esta información se obtiene mediante las propias encuestas del Programa, de las estadísticas de servicios y de otras encuestas nacionales de salud. 


\section{POBLACIÓN BENEFICIARIA}

El Programa es suficientemente flexible para realizar sus actividades en sitios diversos, tales como centros de servicio juvenil, centros de salud, organizaciones juveniles, centros culturales y centros laborales, así como en sedes de otras instituciones que atienden a jóvenes, como los centros de integración juvenil, consejos tutelares, ligas deportivas, servicios médicos generales y escolares, centros de convivencia juvenil, escuelas de educación básica, media y superior, fábricas, comercios, sedes de grupos militares, gremios y sindicatos, clubes, bandas, plazas públicas. Para resumir, se trata de un programa que se lleva a cabo en dondequiera que se encuentre la gente joven.

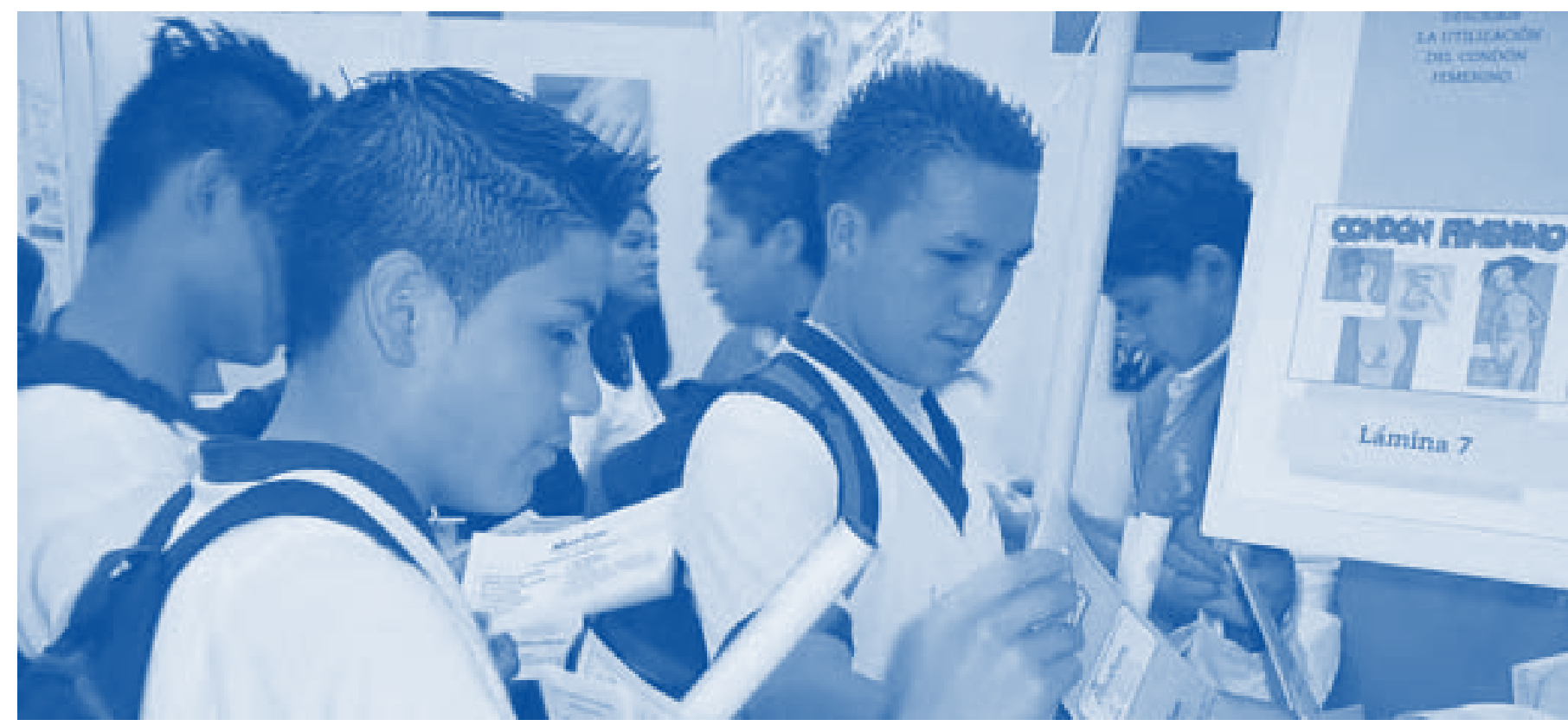

G6 Jóvenes recibiendo educación sexual. 


$$
\begin{array}{r}
\text { IV. DIAGNÓSTICO E } \\
\text { IMPLEMENTACIÓN, } \\
\text { PASO A PASO }
\end{array}
$$




\section{DIAGNÓSTICO FIMPIFMFNTACIÓN}

Al iniciar un programa juvenil es importante realizar un diagnóstico preliminar, ya sea a nivel local o nacional, que permita definir los lugares en donde hay mayores necesidades. Mediante este análisis se obtienen los datos esenciales para establecer las necesidades inmediatas y de largo plazo que se requieran.

Además de recopilar esta información, mediante visitas domiciliarias se aprovecha para dar a conocer el Programa en todos los hogares del área de cobertura definida, para identificar jóvenes interesados en participar como voluntarios y para repartir folletos y otros materiales impresos sobre los servicios que se ofrecen.

En el caso del Programa Gente Joven, dicha estrategia se conoce como Operación de Cobertura Sistemática de Servicios (OCOSIS). Para comprender de mejor manera su implementación, podemos dividirla en los siguientes pasos.

\section{Solicitud de apoyo}

Consiste en investigar quiénes son las autoridades que aprueban la realización de actividades en la comunidad y en las instituciones, y visitarlas para solicitar su apoyo al Programa. Durante la entrevista se explica la importancia de trabajar con jóvenes, los problemas por los que atraviesan, sus necesidades de salud, educación y sociales, así como las labores específicas que se pretenden realizar en la zona. También se puede sondear en qué forma estarían dispuestas las autoridades a participar en las actividades del Programa. Finalmente, se aplica un cuestionario para obtener información sobre la comunidad que permita planear las siguientes dinámicas (ver Apéndice 1).

\section{Formación del equipo básico}

Una vez autorizada la puesta en marcha de actividades, se recomienda formar un equipo con un mínimo de tres personas para llevar a cabo encuestas y labores de información en los hogares. Una buena opción puede ser reclutar a estudiantes que necesiten prestar su servicio social o, cuando sea posible y en un inicio, con personal asalariado.

\section{Trazo de mapas y croquis}

Este paso consiste en elaborar un mapa que incluya las manzanas o viviendas en donde se pretende trabajar y un croquis de cada manzana.

En el caso de poblados rurales y asentamientos urbanos irregulares, se sugiere trazar el mapa o plano desde una zona elevada, o bien recorrer la comunidad a pie para dibujarlo con detalle. Lo ideal es disponer de un mapa ya elaborado en donde se podrá ir insertando la información que específicamente interesa al Programa. 
En cuanto a poblados o ciudades de un tamaño mayor, es preferible acudir a la delegación o municipio correspondiente para solicitar dicho mapa.

En todos los lugares donde se tenga planificado establecer el Programa, la recomendación es cubrir una colonia por mes, iniciando con la más cercana a las instalaciones que funcionan como sede, para ampliar la cobertura mes a mes hacia otras colonias que circunden a la primera.

Para elaborar los croquis, primero se enumeran sistemáticamente todas las manzanas del plano y en el croquis de cada una de ellas se numeran las viviendas.

El croquis también debe identificar la ubicación de sitios que son clave para el desarrollo de las actividades, como escuelas, iglesias, mercados, oficinas de gobierno, domicilio de los actuales promotores juveniles -si los hay-, comercios, farmacias, consultorios, centros de salud, sedes de organizaciones no gubernamentales y otros datos que se consideren pertinentes.

\section{Visitas domiciliarias y registro}

El equipo debe visitar cada vivienda o establecimiento identificados en el croquis. Podemos dividir estas visitas en cuatro rubros:

Hogares. Para cada domicilio se llena una ficha que proporcione la siguiente información:

a) Apellido de la familia y nombre y edad de la persona que la encabeza.

b) Número de personas adultas, jóvenes y menores que integran la familia.

c) Sexo, edad y estado civil (soltero, casado o unido, viudo o separado) de los adolescentes y jóvenes que ahí viven.

d) Actividades que estos jóvenes y adolescentes realizan cotidianamente.

e) Datos que pudieran ser importantes relativos a la salud sexual y reproductiva de los jóvenes y adolescentes, tales como asistencia a la escuela, trabajo, si tienen hijos o no, si pertenecen a algún grupo, etcétera.

Durante las visitas domiciliarias se informa a las familias sobre las actividades que realiza el Programa con escuelas, centros de salud, clínicas, médicos y farmacias amigables, así como la ubicación, horario de atención y costos de los que estén más cerca del hogar visitado. También se pregunta a cada joven si desea tomar un curso sobre sexualidad, participar en otros eventos o colaborar como promotor juvenil. Finalmente, se entrega un folleto sobre el Programa y cualquier otro material impreso que sea relevante. 


\section{DIAGNÓSTICO FIMPIEMENTACIÓN}

Se recomienda que el promotor juvenil que visite los hogares lleve una identificación de la organización que piensa implementar el Programa, idealmente una credencial mostrando su membresía, o bien una gorra o playera con el logo correspondiente.

Escuelas. La identificación de todas las escuelas de la zona es especialmente importante para planear el componente escolar (ver capítulo Componentes del Programa juvenil). Hay que especificar el tipo de escuela de la que se trata: primaria, secundaria, preparatoria, universidad; el número de alumnos y profesores, incluyendo al personal de orientación vocacional que muchas veces son psicólogos y/o trabajadoras sociales, y los nombres del personal directivo. Para cada escuela se recomienda llenar una ficha especial (ver Apéndice 2).

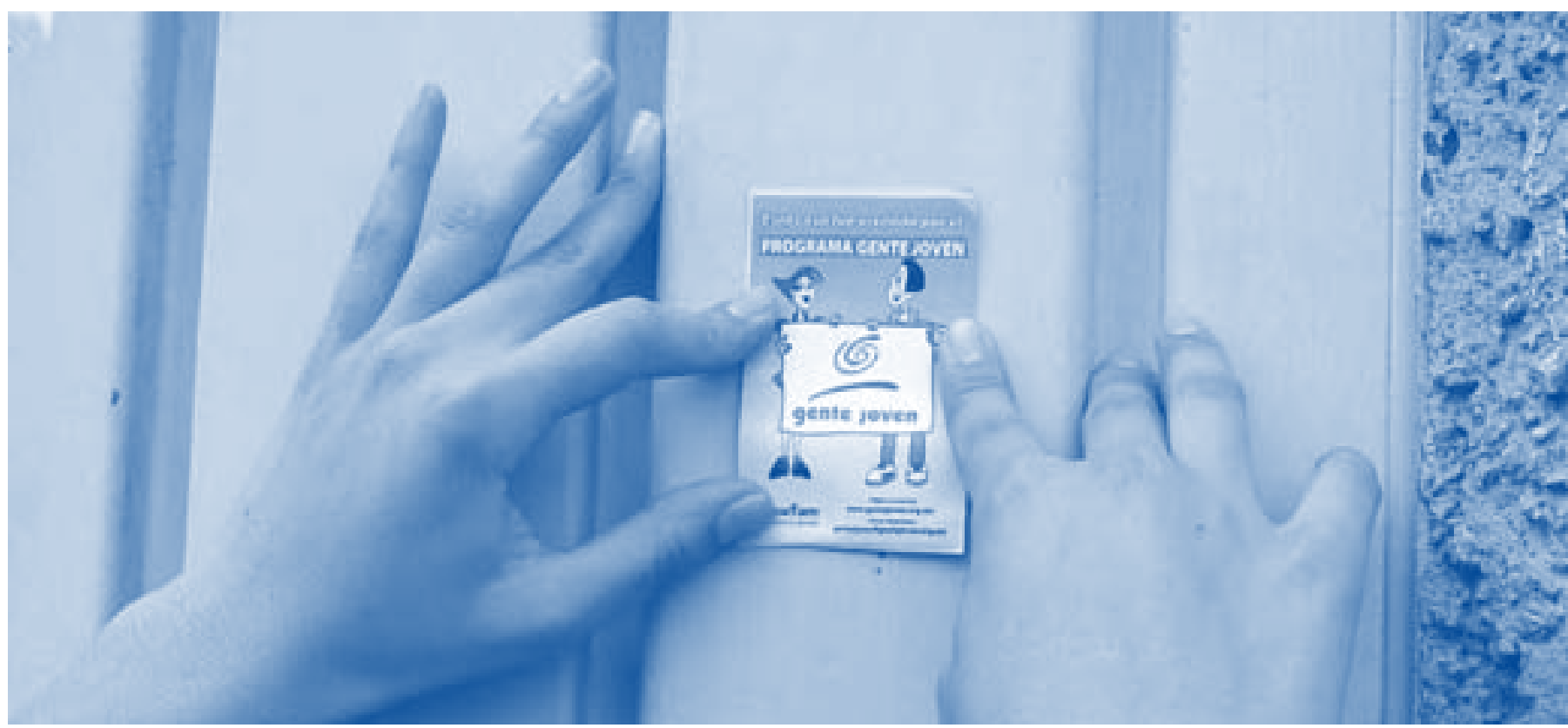

Domicilio visitado. 
Centros de salud y servicios médicos privados. Su registro contribuye a planear el componente médico del Programa (ver capítulo Componentes del Programa juvenil). Hay que indagar si estos servicios de salud ofrecen o no atención a jóvenes y, en caso de no ser así, explorar si estarían interesados en proporcionarlos. Es importante recabar los datos del personal directivo, médico y paramédico que eventualmente estuviera interesado en involucrarse con el Programa. Se recomienda aplicar un cuestionario particular en los centros de salud, clínicas y consultorios de médicos privados (ver Apéndice 3) y otro en las farmacias (ver Apéndice 4).

Otras instituciones. Es fundamental identificar otros sitios e instituciones que pueden llegar a formar parte del Programa, como pudieran ser clubes juveniles, instituciones militares, centros de readaptación social (cárceles), fábricas, ligas y centros deportivos, mercados, parques, cafeterías, salones de baile, bares, discotecas, cafés-Internet, sindicatos, farmacias, instalaciones y clínicas de la institución, y anotar su disposición para participar en actividades del Programa.

\section{Elaboración de encuesta}

Para complementar los datos que se obtienen durante las labores de diagnóstico, se recomienda hacer una encuesta que proporcione información más amplia sobre los habitantes del área.

Es aconsejable entrevistar a 100 jóvenes de entre 10 y 24 años de edad en viviendas elegidas de manera aleatoria. Primero se seleccionan los domicilios, numerando las viviendas del 1 al 4000, y se eligen 150 (considerando que en una proporción de hogares no habitarán adolescentes) mediante una tabla de números aleatorios (disponible en papelerías), con lo que quedan definidas las viviendas a visitar. Después se entrevista a todos los adolescentes y jóvenes que habiten en las viviendas seleccionadas utilizando un cuestionario que recabe datos socio-demográficos, sus conocimientos, prácticas e intereses específicos sobre salud sexual y reproductiva, pasatiempos, actitudes sobre educación y sexualidad, etcétera. También se buscará detectar los grupos y organizaciones juveniles existentes en cada colonia.

Se recomienda que se presenten los resultados de la encuesta a las autoridades civiles, médicas y escolares, y a la población que se contempla como beneficiaria del Programa. 


\section{DIAGNÓSTICO FIMPIFMFNTACIÓN}

\section{Preparación de bases de datos}

Una vez terminada la recopilación de información, una actividad de mucha utilidad es preparar bases de datos con nombres y referencias de contacto de:

- Los jóvenes interesados en participar en las diferentes actividades del Programa y en ser capacitados como promotores juveniles.

- Los promotores juveniles que vaya capacitando el Programa.

- Las instituciones de la sociedad civil de la zona que realizan o están interesadas en realizar trabajo con y para jóvenes en temas de salud y derechos sexuales y reproductivos o de cualesquiera otros temas y con los que se puedan organizar actividades de manera conjunta.

Esto permitirá al coordinador del Programa crear una red de apoyo con las instituciones y personas identificadas en el diagnóstico, e integrar un grupo de jóvenes voluntarios capacitados que se denominan promotores juveniles.

\section{Búsqueda de financiamiento}

Con base en los datos del diagnóstico, se procede a la justificación y delimitación geográfica del Programa, lo mismo que al planteamiento de proyectos que tengan posibilidades de ser financiados por instituciones nacionales $y / o$ internacionales que tengan entre sus prioridades a la gente joven de la zona de influencia o al país.

Los resultados del diagnóstico pasarán a formar parte del expediente técnico, del cual deben tener copia en los niveles administrativos centrales y locales de la institución, e incluir un resumen del proyecto o proyectos que el Programa está realizando, especialmente si alguna agencia donante está patrocinando esta actividad.

\section{Programación de actividades}

Una vez definida el área y la población, es importante que el Coordinador establezca claramente las líneas de acción de acuerdo a principios estratégicos del Programa, a las características y necesidades particulares detectadas en cada lugar, a la creatividad de los promotores juveniles y a las circunstancias específicas bajo las que se pretende trabajar. 


\section{Establecimiento de metas}

Hecho el lanzamiento del Programa, se deben establecer resultados o metas esperadas por área de trabajo, así como los tiempos correspondientes. Se recomienda hacer cronogramas de actividades, en donde puedan observarse las labores programadas y realizadas, por mes y año. Idealmente, estos cronogramas deben estar disponibles en cada espacio que colabore con el Programa; en ellos deben incluirse también los nombres de los responsables respectivos por tarea.

Entre los resultados que se fijen en prestación de servicios, podrían considerarse:

- Número de jóvenes informados en salud sexual y reproductiva y temas afines, por mes y año.

- Número de métodos anticonceptivos distribuidos y sus correspondientes años-protección-pareja (APP), por mes y año.

- Número de docentes capacitados por año y de escuelas participantes en el Programa.

- Número de médicos y paramédicos capacitados anualmente y de centros de salud, clínicas, médicos particulares y empleados o dueños de farmacias participantes en el Programa.

- Número de servicios médicos prestados, por mes y año.

- Número de servicios de orientación-consejería proporcionados a jóvenes y adolescentes, por mes y año.

- Número de consultorios con médicos capacitados como "médicos amigables". 


\section{COMPONENTES DEL PROGRAMA JUVENIL}


El Programa juvenil opera a través de tres componentes, es decir, se desarrolla en varios ámbitos; si bien cada uno cuenta con sus propias características y actividades, se complementan y trabajan entre sí.

El siguiente cuadro muestra de manera gráfica los componentes del Programa. Posteriormente explicaremos cómo se implementan.

\section{COMPONENTES DEL PROGRAMA JUVENIL parte 1}

\section{Comunitario}

\section{Escolar}

\section{PARTICIPANTES}

- Coordinadores

- Promotores juveniles

- Jóvenes que no asisten a escuelas

- Jóvenes que trabajan formal o informalmente
- Coordinadores y promotores juveniles

- Maestros

- Alumnos

- Padres y madres de familia

\section{OPERACIÓN}

\section{- Espacios amigables}

\section{Actividades:}

- Ligas deportivas

- Cine-debate

- Discotecas y bares

- Teatro

- Baúl de auto-aprendizaje

- Participación comunitaria en medios de comunicación

- Concursos de grafiti

- Módulos informativos

- Concursos y actividades con otras instituciones

- Periódicos murales

- Desfiles y marchas

- Brigadas de salud

- Café internet

- Condonerías

- Condonería móvil

- Otras actividades
- Selección de escuelas

- Selección de maestros

- Participación de madres y padres de familia

- Intervención directa del Programa juvenil en las escuelas

- Intervención indirecta en las escuelas, a través de maestros capacitados

- Evaluación de maestros multiplicadores 


\section{COMPONENTES DEL PROGRAMA JUVENIL parte 2}

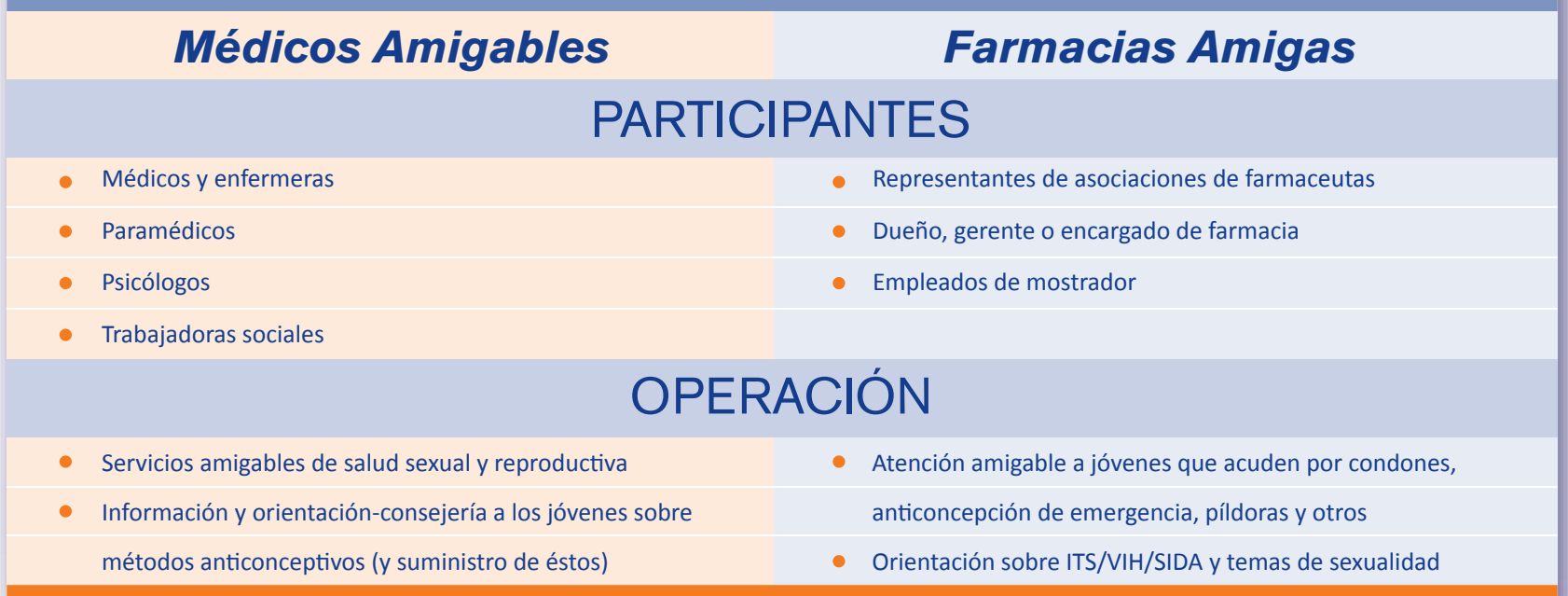

\section{COMPONENTE COMUNITARIO}

Este componente se dirige principalmente a los jóvenes que no asisten a la escuela, ya sea porque trabajan de manera formal o informal o porque simplemente dejaron de asistir al colegio sin haberse incorporado a la fuerza laboral. Representa una prioridad del programa e implica que se busquen los puntos de reunión y los horarios adecuados de estos jóvenes no escolarizados.

Dicha estrategia la manejan de forma predominante los promotores juveniles voluntarios, quienes son la base y fortaleza para establecer y mantener el trabajo del programa.

Por eso, una de las responsabilidades y tareas permanentes de los coordinadores comunitarios y de los propios promotores juveniles es identificar continuamente promotores potenciales, buscando que tengan el perfil adecuado.

\section{OBJETIVOS}

- Brindar información y facilitar la toma de decisiones sobre salud sexual y reproductiva a los jóvenes.

- Crear un clima social donde haya apoyo a la difusión de información y a la realización de eventos, y generar actitudes positivas hacia las actividades del programa. 
- Proporcionar orientación sobre sexualidad a los jóvenes en sus lugares de reunión a través de una gran variedad de actividades comunitarias, que sean creativas y muy "en la onda".

- Organizar el trabajo de difusión y gestión de recursos y espacios en el seno de las instituciones.

- Promover el trabajo en redes interinstitucionales para apoyar la convocatoria y reunión de jóvenes en distintas actividades, como ferias de salud, marchas cívicas, concursos, desfiles, entre otras.

\section{¿DÓNDE SE DESARROLLA?}

La estrategia comunitaria se desarrolla en los diferentes lugares que se han identificado en la etapa de diagnóstico como aquellos donde la gente joven se reúne. La información sobre estos puntos de reunión debe actualizarse de manera permanente con los datos proporcionados por los promotores y coordinadores.

Estos sitios incluyen:

- centros deportivos

- lugares de diversión y recreación

- reclusorios

- la calle (donde se puede acceder a bandas, pandillas y empleados en el sector informal)

- fábricas

- empresas familiares

- albergues

También se desarrolla en los lugares donde se puedan encontrar madres y padres adolescentes que forman parte de redes comunitarias.

\section{OPERACIÓN}

\section{A. Espacios amigables}

El Programa juvenil llama "espacios amigables" a aquellos lugares identificados por los promotores voluntarios y el coordinador que permiten el acceso a información y orientación-consejería. En ellos se pueden reunir de manera informal y hablar de los temas que interesan a los jóvenes. Se realizan actividades que fomentan el intercambio libre de ideas con énfasis en la salud sexual y reproductiva. 


\section{COMPONENTES DELLROGRAMA JUVENII}

Los espacios amigables pueden construirse en un sitio privado dentro de clínicas del Programa, en locales que las autoridades o personas particulares presten a los jóvenes para reunirse, o en otras instituciones que tengan programas juveniles y cuenten con un área disponible.

\section{B. Actividades}

En este componente hay un campo amplio para que el coordinador y los promotores juveniles ideen estrategias creativas para trabajar de manera efectiva y eficiente con los jóvenes. Las experiencias son muy variadas y continuamente enriquecen la gama de actividades posibles. Las diferentes dinámicas tienen como esencia la entrega de información en lugares que permiten el libre intercambio de ideas y el acceso a información veraz.

A continuación explicamos las actividades que ha implementado el Programa juvenil en lugares como ligas deportivas, discotecas y salones de baile, salas de conciertos de música, cafés Internet, billares, etcétera.

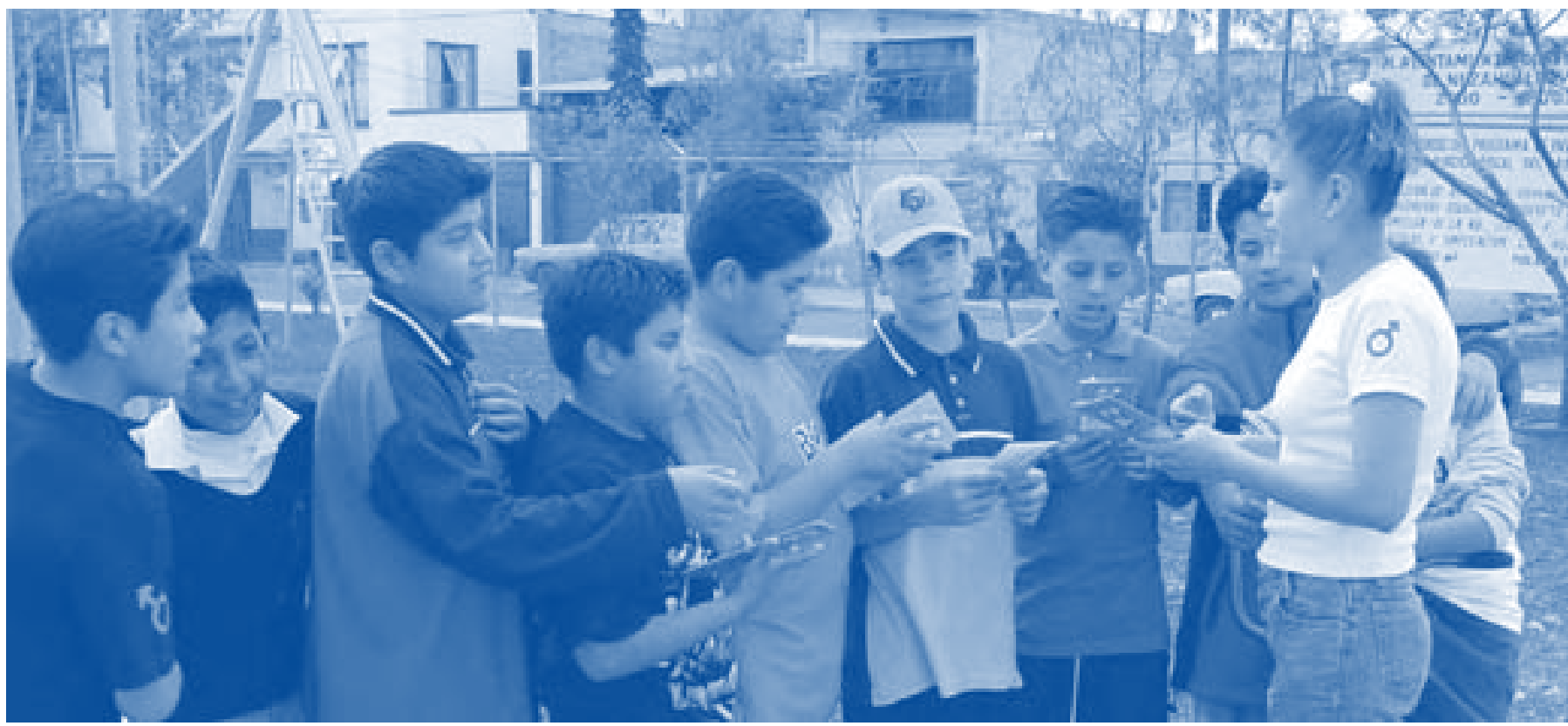

(G) Promotora proporcionando información a jóvenes interesados. 


\section{Más ideas}

- Organizar torneos en centros deportivos, escuelas o cualquier otro sitio pertinente, convocar a equipos interesados y programar actividades informativas para los participantes.

- Los días en que se llevan a cabo las actividades deportivas, instalar un módulo de información para distribuir folletos, materiales educativos y condones, y para promocionar cursos, pláticas y la anticoncepción de emergencia.

- Aprovechar los recesos para montar tablas gimnásticas o porras. Mediante altavoces o sonidos, difundir mensajes relacionados con los temas del Programa. Es importante que los promotores juveniles se identifiquen con camisetas y gorras del Programa.

- Cuando sea posible, patrocinar un equipo, apoyándolo con el uniforme. También se puede distinguir a la mejor escuadra del torneo obsequiándole camisetas, calcetas y shorts con el logo del Programa, balones profesionales y trofeos.

- Es importante mencionar que si se cobran cuotas de recuperación en los torneos, éstas deberán ser accesibles.

\section{Cine-debates}

\section{Propósito de la actividad}

Exponer de manera lúdica los temas de actualidad para los jóvenes en materia de salud sexual y reproductiva, derechos y problemas sociales, para discutirlos con personas capacitadas que puedan responder a las dudas y ampliar la información. Es también una buena ocasión para invitar a los jóvenes a participar en el Programa.

\section{Cómo se realiza la actividad}

Se planea la exhibición de las películas, estableciendo lugar, fecha y hora para la proyección. Si el Programa dispone de un espacio propio, lo ideal es realizar ahí la sesión; de no ser así, habrá que hacer contacto con la persona responsable del lugar en donde se hará la exhibición y acordar con ésta los detalles pertinentes, incluyendo el acuerdo para el préstamo del espacio, el personal y el equipo que serán necesarios.

Las películas pueden ser comerciales o producidas por el Programa (ver Apéndice 7), que presenten problemáticas comunes de los adolescentes. Es importante seleccionar cintas que sean interesantes para los jóvenes, con temas relacionados con sus necesidades, para asegurarse que estarán dispuestos a debatir.

La persona o los promotores juveniles que realicen los cine-debates tienen que analizar previamente la película, asesorarse con una persona capacitada en el tema y, si es necesario, invitarla a que participe en la sesión. Se procurará que la persona invitada conozca el Pro- 
grama y los enfoques de la institución, y que pueda responder o comentar los planteamientos que los jóvenes hagan. Será importante tener a mano información relacionada con el Programa. Se recomienda igualmente que antes de la proyección se prepare una guía para iniciar la discusión.

\section{Más ideas}

- Promover los cine-debates colocando anuncios visibles en sitios concurridos, como escuelas, parques, cafeterías, cafés Internet y otros frecuentados por jóvenes en la comunidad, y anunciarlos por estaciones locales de radio, dando información del ciclo completo de películas (de ser el caso) y de las fechas, horas y lugares que correspondan.

- Considerar la proyección de una o varias películas durante algún viaje o trayecto en autobús. Al terminar la película, se haría el debate con los viajeros que deseen participar. Durante la actividad, la persona a cargo deberá portar algún distintivo que lo identifique como miembro del Programa.

\section{Discotecas y bares}

\section{Propósito de la actividad}

Poner información sobre sexualidad, métodos anticonceptivos, condones y anticoncepción de emergencia a la disposición de las personas jóvenes en las discotecas o bares donde se reúnen.

\section{Cómo se realiza la actividad}

Para iniciar la actividad habrá que localizar las discotecas o bares del área de influencia y realizar una visita para saber si asiste la gente joven y conocer su horario de funcionamiento. Luego se establece contacto formal con el dueño, administrador o encargado del lugar y se le dan a conocer los objetivos y actividades que el Programa lleva a cabo, mencionando la importancia de contar con espacios para distribuir información y anticonceptivos, especialmente condones y anticoncepción de emergencia. Si se establece un buen contacto con los responsables, se pueden explorar otras posibilidades y conseguir información de otros sitios similares que pudieran estar interesados en facilitar la presencia del Programa.

Una vez que se han obtenido las autorizaciones correspondientes, se programan en detalle las actividades a realizar en las discos y bares, estableciendo, por ejemplo, qué días y en qué horarios estarán los promotores juveniles en el módulo de información, presentarán videos o audio, o distribuirán condones.

\section{Más ideas}

- Dado que las discos y bares son lugares que abren por las noches, es pertinente que 


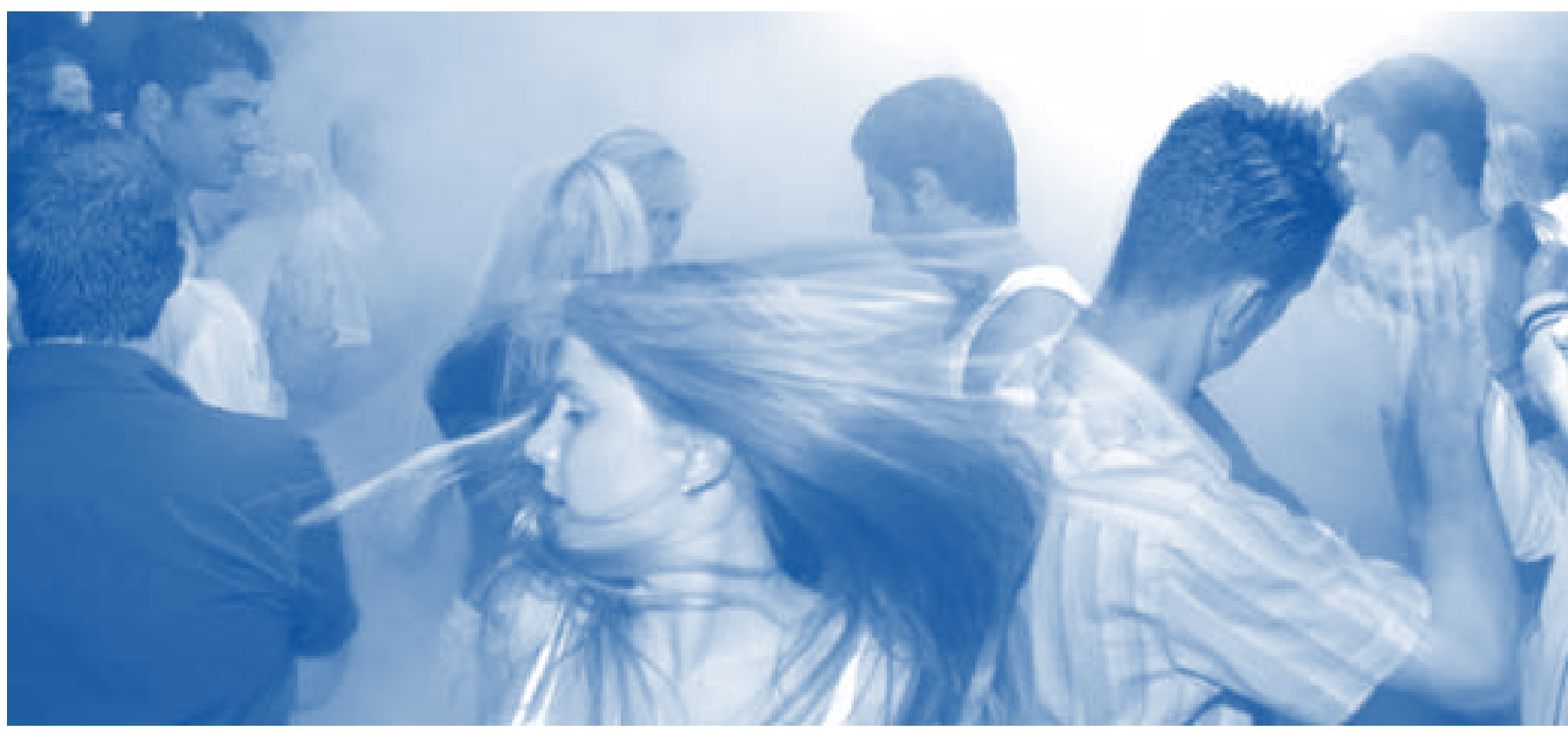

Góvenes en discoteca.

cada equipo de trabajo incluya cuatro personas entre las que haya por lo menos un hombre; con ello se evitarán hostigamientos o agresiones que pudieran llegar a ocurrir si el equipo lo integraran solamente mujeres. Desafortunadamente, todavía las mujeres que van solas a discos y bares son estigmatizadas y muchas veces acosadas.

- Antes de que abra la disco o el bar al público, colocar carteles con información sobre salud sexual y reproductiva en lugares visibles y en los sanitarios.

- En la parte externa del lugar, preferiblemente a la entrada y en un lugar suficientemente iluminado, ubicar el módulo de información, el cual puede exhibir condones, lubricantes, sexy packs, guantes, dedales y anticoncepción de emergencia. Los promotores encargados del módulo deberán anticipar la disponibilidad de un vehículo a fin de poder transportar todo el material y para su propia seguridad.

- Tener disponibles condones y otros productos que generalmente se expenden sólo en lugares como las sex shops, suficientemente novedosos para que atraigan a las personas jóvenes al Programa.

- Organizar un concurso de habilidades para ponerse un condón con la boca, con los codos o cualquier otra parte del cuerpo; se puede pensar de manera creativa en otros 
temas para este mismo fin. Los ganadores deben explicar también cómo se usa el condón correctamente. El premio pudiera ser alguno de los productos más llamativos del módulo.

- Ubicar un espacio disponible dentro de la discoteca para proyectar un video informativo sobre anticoncepción de emergencia, que deberá ser breve pero reiterativo. Las imágenes deben ser muy llamativas y carecer de sonido para que al mismo tiempo que los jóvenes bailan o escuchan la música, puedan percibir y entender la información.

\section{Teatro}

\section{Propósito de la actividad}

Romper con tabúes que aluden a la sexualidad en general y divulgar información correcta, especialmente sobre salud sexual y reproductiva de la gente joven.

\section{Cómo se realiza la actividad}

El trabajo con jóvenes interesados en la actividad de teatro tiene que tomar en cuenta sobre todo su interés por participar en ella, sus habilidades específicas, y sus facultades para improvisar y presentarse en público, así como su disponibilidad de tiempo para la capacitación y ensayos. Es por ello que los promotores juveniles más experimentados y dispuestos serán los idóneos para capacitar a los jóvenes en técnicas de improvisación, de respiración, argumentos, ejercicios de memoria y de expresión corporal.

Los jóvenes pueden hacer los guiones según sus inquietudes y creatividad. Sin embargo, éstos deberán ser revisados y aprobados por personas capacitadas en el tema a tratar, para asegurar que el mensaje sea claro y siga los lineamientos del Programa.

En los casos de teatro guiñol y de sombras es necesario organizar primero un entrenamiento básico en estas dos técnicas mediante un taller y, a partir de eso, planear el guión y la exhibición.

\section{Más ideas}

- Si lo prefieren, utilizar algún guión ya existente y adaptarlo de acuerdo a situaciones actuales.

- Al término de la obra, hacer un debate, una sesión de preguntas y respuestas o una presentación de uno o dos comentaristas sobre los mensajes básicos y la relevancia de la obra presentada. 


\section{Baúl de auto-aprendizaje en salud sexual y reproductiva}

\section{Propósito de la actividad}

Generar un espacio creativo de auto-aprendizaje en salud sexual y reproductiva en lugares a donde acuden los jóvenes, por medio de materiales interactivos que pueden ser desarrollados por ellos mismos.

\section{Cómo se realiza la actividad}

Para llevar a cabo esta actividad, se tendrán en cuenta los siguientes cinco pasos básicos: 1) construcción, 2) gestión comunitaria, 3) taller de capacitación, 4) informe de gestión y 5) evaluación.

\section{1) Construcción}

Un baúl es un mecanismo que permite el auto-aprendizaje de temas de salud sexual y reproductiva. En términos generales, es un recipiente en donde se ponen objetos de diferentes

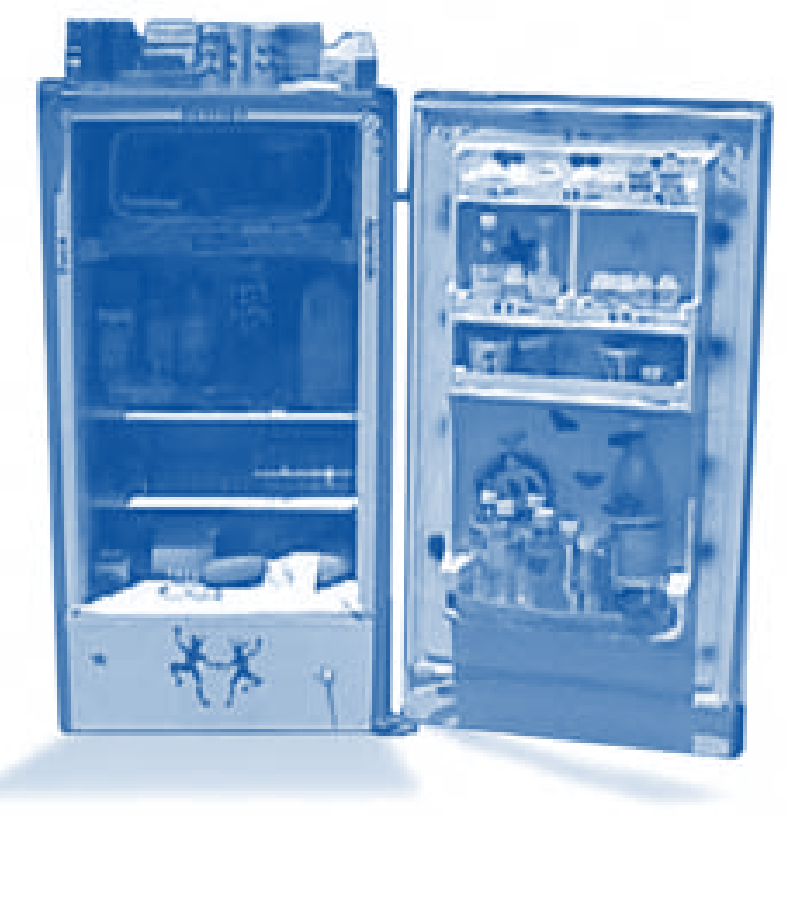


tipos con información relacionada a las preguntas más frecuentes que tienen los jóvenes sobre sexualidad. Pueden ser frascos, tubos de pintura de labios, cajas de CD o de cerillos, frascos de medicina o cualquier otro objeto. Adentro se pone un papel con una pregunta, cuya respuesta va a encontrar en el mismo baúl pero en otro objeto, pues debe diferenciarse un área para preguntas y otra para respuestas.

El baúl también está organizado por temas. Por ejemplo, se puede poner una sección de objetos con preguntas y respuestas exclusivamente sobre ITS/VIH/SIDA.

Existen tantos modelos de baúl de auto-aprendizaje como dicte la creatividad de los promotores juveniles. Puede ser un puesto de periódicos o uno de tianguis (mercado), una cabaña, un prisma, un armario, un refrigerador, una mochila o cualquier otro "recipiente" (de preferencia reciclable) en donde se puedan poner los objetos con las preguntas, respuestas y la información en general. El baúl es un instrumento siempre disponible para dar cabida a más información y para ofrecer respuestas una y otra vez.

Para su diseño se buscará a aquellos jóvenes que sean hábiles para el dibujo, la construcción y la decoración. Los mejores pintores se pueden encargar de la portada; o bien se puede forrar el baúl con fieltro o papel, o se le puede pegar algún collage alusivo. La idea es crear un modelo práctico, colorido y atractivo para llamar la atención de todos.

Un equipo se hace cargo de la construcción del baúl, asistido por el coordinador de cada lugar, quien define los materiales que son necesarios para hacerlo y los adquiere, todo dentro del presupuesto que se haya definido para la actividad.

Se recomienda que el baúl sea ligero y de tamaño manejable para permitir su traslado con facilidad a parques públicos, bibliotecas, comunidades, escuelas, centros de salud y cualquier otro lugar donde se puedan efectuar actividades comunitarias.

\section{2) Gestión comunitaria}

El coordinador del Programa y los promotores juveniles serán responsables de integrar un equipo de gestión formado por voluntarios que promueven los servicios, invitan a la comunidad a usar el baúl y definen los horarios de atención. Los voluntarios que atiendan el baúl deben rotarse en los horarios de atención, llevar una bitácora de uso y evaluar los resultados, anotando cuánta gente lo visitó y pidió información, qué materiales fueron los más atractivos, los más usados, las preguntas más frecuentes y las características de los asistentes. Al finalizar cada mes, darán a conocer los resultados del uso del baúl, así como sus apreciaciones e ideas para mejorar la interacción entre el baúl y sus usuarios. Es recomendable una cierta continuidad del equipo de gestión del baúl. Se sugiere que se asuma esta responsabilidad al menos durante un mes, al término del cual se renovará al equipo responsable. Este equipo hará entonces la difusión del baúl y con las sugerencias del grupo 
anterior, propondrá nuevas alternativas o sugerencias que hayan recibido para mejorar o actualizar la información, los temas, las imágenes y los recursos. Cada vez que cambie el equipo, el grupo saliente debe capacitar al nuevo equipo a fin de avanzar sobre un proceso en marcha y evitar que se repitan errores ya superados.

Es probable que durante la operación del baúl haya personas de la comunidad que quieran integrarse al equipo de gestoría, lo cual puede convertirlo en una actividad de integración comunitaria.

\section{3) Taller de capacitación}

La capacitación se realiza mediante una sesión de auto-aprendizaje acompañada por promotores experimentados o por el coordinador. Los aspectos que se deben abordar son, entre otros: cómo buscar la información; cómo conversar sobre temas de interés; cómo seleccionar temas de interés y cómo abordarlos de manera adecuada; qué habilidades o conocimientos se obtienen del recorrido por los contenidos del baúl; qué otras alternativas se pueden considerar. El equipo analizará cada parte del baúl y propondrá ideas para mejorarlo, ya sea modificando la forma en que la información se presenta, sus contenidos, la presentación del baúl o cualquier aspecto relacionado con la actividad.

Es esencial que el equipo de gestión conozca todos los elementos del baúl para que pueda responder a las dudas y comentarios de las y los usuarios.

Puede ocurrir que los jóvenes acudan al baúl buscando información que les es solicitada en su escuela. Tal circunstancia puede aprovecharse para darles la información que requieren y ver la posibilidad de organizar un taller, ya sea en el colegio o en un "espacio amigable", para obtener enfoques e ideas no considerados durante la elaboración y presentación de los temas.

\section{4) Evaluación del baúl}

La evaluación del baúl deberá hacerse con suficiente anticipación para que el equipo gestor realice los cambios propuestos por el público. De esta manera, el equipo de relevo dispondrá de un baúl más rico en información y listo para nuevas sugerencias.

Para valorar la utilidad del baúl en la comunidad se deberán realizar dos tipos de evaluaciones: una cuantitativa y otra cualitativa. Para la cuantitativa, se define el número, sexo y edad de las personas que consultan el baúl por semana y mes; el tiempo promedio que lo usaron; los temas consultados más a menudo; los motivos de las consultas; los materiales más atractivos; qué se puede agregar o quitar al baúl, y cuáles son las preguntas más comunes. El Programa utiliza una forma sencilla para recabar esta información, misma que brinda a todas las personas que consultan el baúl (ver Apéndice 5). 
La evaluación cualitativa puede usar formularios de auto-llenado, solicitando información sobre la emoción, aprendizaje, sugerencias y comentarios (ver Apéndice 6).

Esta evaluación también se puede aplicar a una muestra aleatoria de participantes, por ejemplo, a uno de cada tres o de cada cinco, dependiendo del flujo de visitantes.

Otra opción de evaluación es que el equipo tenga un cuaderno-diario, o la bitácora que se mencionó anteriormente, donde registre los incidentes o anécdotas del uso de los materiales: ¿Cuáles son las dificultades para acercarse al baúl? ¿Qué actitudes tienen los usuarios con el baúl la primera vez y las subsecuentes, si las hay? Cada mes se deben revisar los comentarios y propuestas de los visitantes.

\section{5) Informe de gestión}

El equipo encargado deberá, al término de su gestión, elaborar y dejar un registro de respuestas a las preguntas que se sugirieron en párrafos anteriores y proceder a reforzar y enriquecer la información y los recursos que indique la evaluación.

\section{Participación comunitaria en medios de comunicación}

\section{Propósito de la actividad}

Acercarse a los medios de comunicación para generar espacios de promoción en prensa escrita, radio o televisión local o abierta.

\section{Cómo se realiza la actividad}

Puede hacerse en dos modalidades: como organización invitada a programas de opinión, o como generadora de sus propios programas y mensajes, incluyendo la difusión gratuita de invitación a eventos. De manera extraordinaria se podrían pagar inserciones para promover alguna actividad del Programa u organizar una conferencia de prensa sobre un tema determinado. Los tipos de medios que suelen usarse en el componente comunitario son:

- Radio, muy útil para promover los servicios que ofrece la institución, especialmente en clínicas, tanto en localidades pequeñas como en ciudades intermedias o grandes, y para convocar a la población a participar en actividades comunitarias, obras de teatro, cine-debates, pláticas, cursos o programas dedicados a la gente joven en temas de salud sexual y reproductiva.

- Televisión, en donde la opción sería participar en calidad de entrevistado en algún noticiero, reportaje especial, cápsula informativa, programa educativo y otros, o con los materiales de la institución, a los cuales se puede hacer referencia.

- Conferencias de prensa, que pueden ser organizadas y convocadas directamente por el Programa o en coordinación con las redes interinstitucionales de colaboración. Tienen 
un buen impacto en los medios, ya que permiten escuchar la opinión o las posturas de los jóvenes ante diferentes temas que suelen causar controversia en la sociedad: acceso a servicios de salud sexual para adolescentes, educación sexual, uso del condón, de pastillas de anticoncepción de emergencia, entre otros.

- Prensa, mediante entrevistas que se ofrecen sobre temas del Programa, fechas alusivas, artículos especializados y boletines, todos relacionados con la salud sexual y reproductiva de los jóvenes.

- Internet, que por ser un medio altamente utilizado por los jóvenes resulta un excelente vehículo de comunicación. Se puede contar con páginas en sitios de Internet propios del Programa o promover el uso de los vínculos de las páginas especializadas ya existentes, con el fin de que los jóvenes puedan acceder a información actualizada que responda a sus dudas e inquietudes de manera personalizada. El Programa ofrece una opción a través de su sitio: www.mexfam.org.mx

\section{Concursos de grafiti}

\section{Propósito de la actividad}

Atraer a más jóvenes, sobre todo a quienes no es fácil encontrar en los lugares tradicionales, extendiendo así el área de influencia del Programa y abarcando la diversidad juvenil.

\section{Cómo se realiza la actividad}

Para llevar a cabo esta actividad, se tendrán en cuenta los siguientes seis pasos básicos: 1) selección de la barda, 2) solicitud de permisos, 3) convocatoria a jóvenes, 4) gestión administrativa, 5) implementación, 6) jurado calificador.

\section{1) Selección de la barda}

Para pintar los grafiti deberá localizarse una barda en un espacio abierto con gran afluencia de visitantes o transeúntes y dentro del área de influencia del Programa. Cuando no sea posible disponer de una barda, el concurso de grafiti se puede hacer en diversos materiales, como mantas o papel.

\section{2) Solicitud de permisos}

Para evitar problemas, se asegurará disponer del permiso de los dueños de las bardas y de las autoridades correspondientes: delegado, presidente municipal, alcalde, funcionario o dependencia a cargo del medio ambiente y otros.

\section{3) Convocatoria a jóvenes}

La convocatoria será lo más amplia posible para los jóvenes que tengan las habilidades e 
interés en participar en el concurso, incluyendo a personas que se dedican al grafiti y que, por lo general, ya están organizadas.

\section{4) Gestión administrativa}

Es importante buscar el patrocinio de la actividad de los grafiti en instituciones públicas y privadas, empresas y tiendas locales.

\section{5) Implementación}

El coordinador o promotor voluntario programará un curso o taller sobre los temas de la salud sexual y reproductiva, para que los participantes se familiaricen con ellos. A este evento asisten todos aquellos que deseen participar en el concurso. Las tareas que hay que realizar son las siguientes: a) previo a la actividad, dividir la barda autorizada en partes iguales para cada participante, apartando un espacio para la colocación de logotipos de patrocinadores y del evento, actividad que estará bajo la responsabilidad de los promotores juveniles; b) colocar en un punto concurrido, un módulo de información que lleve material impreso y condones, y que anuncie la actividad; c) anunciar a los participantes que deben inscribirse lo antes posible y solicitar una cuota de recuperación mínima; d) incluir en las convocatorias y materiales, las fechas y horarios de los concursos, que en promedio duran entre 4 y 6 horas.

\section{6) Jurado calificador}

Estará conformado por representantes juveniles con conocimientos y trayectoria de grafiti y serán invitados con suficiente anticipación para que asistan y califiquen los trabajos del concurso; las autoridades del Programa juvenil formarán parte de ese jurado también. Se deben evaluar tanto la ejecución artística como el mensaje del grafiti relacionado con algún tema de interés del Programa; los autores deberán explicar al público cómo interpretaron el mensaje, el cual podrán ampliar los miembros del jurado.

\section{Más ideas}

- Encauzar las actividades de los jóvenes aficionados al grafiti organizando un taller de capacitación donde los maestros podrían ser aquellos participantes y ganadores de concursos previos que acepten enseñar a otros. Como en todas las actividades que promueve el Programa, este curso-taller ayudará a complementar la capacitación en los temas de salud sexual, salud reproductiva, sexualidad y derechos de los jóvenes. Al mismo tiempo, se podría aprovechar la ocasión para instalar un taller de aerografía en el que se elaboren las camisetas del programa local.

- Al término del concurso, exhibir los trabajos participantes que se hayan realizado en mantas u otro material, en salas de espera o pasillos de clínicas, espacios juveniles, 


\section{COMPONENTES DEL_PROGRAMA JUVENII}

quioscos y otros sitios públicos, lo mismo que en el sitio de Internet de la institución y de otras organizaciones afines, para ampliar la difusión del trabajo juvenil.

La institución, a su vez, estará abierta a difundir a través de los medios los trabajos que realicen otros programas con los que colabora. Puede incluso pensarse en montar una "exposición de grafiti" que reúna trabajos múltiples, y en promover los grafiti elaborados en bardas para que la gente los visite. De igual manera se pueden difundir sus fotos por los medios electrónicos.

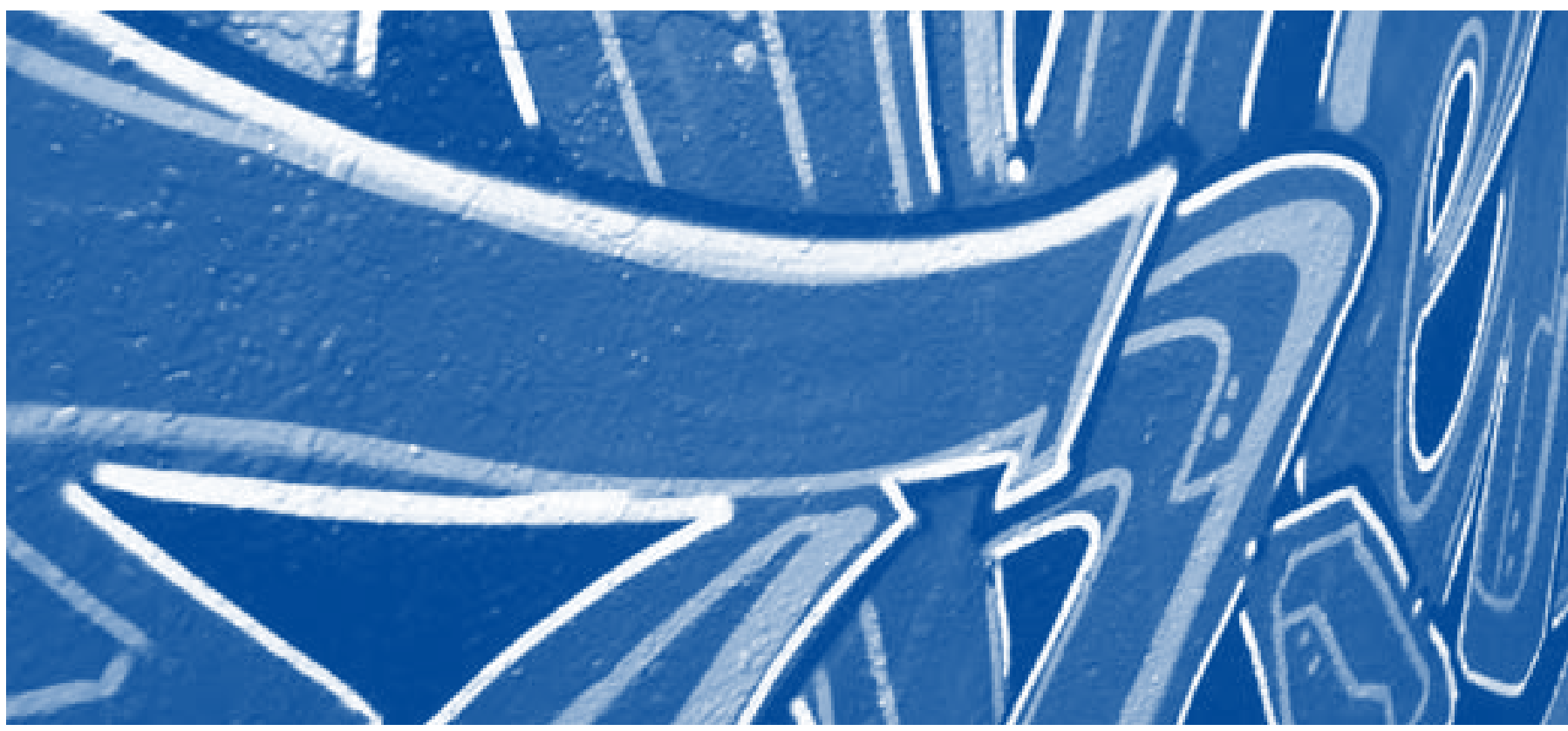

(6) Arte grafiti.

\section{Módulos informativos}

\section{Propósito de la actividad}

Aprovechar cualquier espacio o actividad comunitaria para instalar un módulo y proveer información, promover las actividades, y ofrecer los productos de condonería y las publicaciones y materiales educativos del Programa.

\section{Cómo se realiza la actividad}

Los módulos se colocan durante las actividades públicas, interinstitucionales o específicas del Programa. Son como cualquier módulo de información, pero con contenidos educativos y material anticonceptivo. 


\section{Concursos y actividades con otras instituciones}

\section{Propósito de la actividad}

Brindar apoyo logístico y sustantivo a otras instituciones con las que el Programa forme una red o grupo interinstitucional, en la organización de eventos conmemorativos de fechas internacionales o nacionales con un significado en materia de salud reproductiva.

\section{Cómo se realiza la actividad}

Se llevan a cabo los eventos y se aprovechan para difundir información a través de módulos, donde se regalan y/o venden materiales impresos, lúdicos y métodos anticonceptivos, además de proporcionar más datos sobre el tema principal de la jornada.

\section{Más ideas}

- Organizar actividades artísticas y musicales, en el marco de la colaboración interinstitucional, como tocadas de música de moda entre los jóvenes, exhibiciones de muestras de pintura, dibujo y fotografía sobre los temas del Programa y las culturas juveniles, así como sesiones de canto y conferencias interactivas.

\section{Periódicos murales}

\section{Propósito de la actividad}

Los periódicos murales, además de una fuente de información, han demostrado ser detonadores importantes de preguntas relacionadas con los temas de salud sexual, salud reproductiva, derechos y sexualidades que se trabajen en el Programa, así como de las actividades que se realizan. Como resultado, más jóvenes acuden a los espacios juveniles o clínicas por información o servicios.

\section{Cómo se realiza la actividad}

Se colocan en escuelas, clínicas y en los "espacios amigables". En ocasiones, pueden colocarse en otros sitios donde se reúnen los jóvenes, en espacios recreativos, centros de cómputo o cafés Internet y en clínicas o farmacias, si lo permiten.

\section{Desfiles y marchas}

\section{Propósito de la actividad}

Estas actividades suelen realizarse en el contexto de conmemoraciones cívicas y comunitarias, y se aprovechan para informar y defender los derechos sexuales y reproductivos en general y de los jóvenes en particular, la diversidad sexual, la despenalización del aborto, la no violencia, o la prevención del VIH/SIDA y otras ITS. 


\section{Cómo se realiza la actividad}

Cuando se puede participar en marchas, se incluye información en carteles y mantas a favor de los derechos de la gente joven y como parte de una movilización ciudadana convocada por organizaciones de la sociedad civil o por el Programa mismo. También puede aprovecharse para promover el condón y otros métodos que son más usados por los jóvenes, desplegando modelos gigantes que al ser observados por toda la comunidad le proporcionan un acercamiento lúdico que ayuda a aumentar la legitimidad y naturalidad del uso del método.

\section{Brigadas de salud}

\section{Propósito de la actividad}

Las brigadas de salud son grupos interdisciplinarios que incluyen a profesionales de la salud, así como a psicólogos, trabajadoras sociales, promotores juveniles y al coordinador del Programa para que evalúen y refieran a la población a servicios de salud que no se pudieran brindar en estos sitios itinerantes.

\section{Cómo se realiza la actividad}

Se llevan a cabo en comunidades, escuelas o plazas públicas para prestar servicios de salud integral a los jóvenes. Dicha atención generalmente no está disponible en la localidad y a menudo se hacen referencias y citas en coordinación con otras instituciones del sector salud.

\section{Café Internet}

\section{Propósito de la actividad}

El café Internet ofrece una gran oportunidad de contacto con los jóvenes debido a la enorme demanda del Internet para consultar información para tareas escolares y para diversión. Por esta razón, se pueden ofrecer productos a la venta, incluyendo condones y pastillas de anticoncepción de emergencia, videos y $\mathrm{CD}$, folletos, libros y otros materiales impresos, y recomendar páginas afines a los intereses del Programa u ofrecer protectores de pantallas con mensajes relacionados con la salud sexual y reproductiva.

\section{Cómo se realiza la actividad}

Aunque varios programas han logrado establecer y administrar cafés Internet con sus promotores juveniles, resulta más fácil coordinar la actividad con los dueños y administradores de cafés Internet ya establecidos.

Sin embargo, es importante mencionar la experiencia de un café Internet del Programa que ha logrado ser sostenible por más de cinco años. El éxito de esta experiencia se debe a la 
establecimiento como un lugar que también ofrece métodos anticonceptivos y productos lúdicos. Esta estrategia aumenta la oferta y satisface las necesidades de quienes acceden a este espacio sin descuidar el enfoque primordial de la condonería, que es suministrar condones, material educativo y erótico, y accesorios para actos sexuales más placenteros y sin riesgos.

\section{Cómo se realiza la actividad}

Para establecer una condonería, los recursos mínimos necesarios incluyen un local suficientemente amplio y bien ubicado (en un espacio concurrido), exhibidores de condones, mostrador para las ventas, aparadores o vitrinas para mostrar la mercancía, modelos de pene y vulva, muestrario de condones y lubricantes, materiales educativos, juguetes sexuales, diversidad de métodos anticonceptivos; y en la medida de lo posible tener televisión, DVD, un espacio para orientación-consejería y un baúl de auto-aprendizaje.

Antes de abrir una condonería, es necesario que la persona responsable del Programa y su equipo de voluntarios hagan un estudio de mercado; posteriormente, crearán la imagen de la condonería, buscarán un espacio apropiado y realizarán una buena promoción en diversos medios locales para que la gente joven acuda sin temores. Es importante para el sostenimiento de la condonería buscar a los proveedores que ofrezcan precios reducidos para que los productos estén al alcance de la población más vulnerable y con menores recursos, en especial los jóvenes.

La persona responsable del Programa convocará a los promotores juveniles que tengan habilidades en diseño para planear juntos la imagen de la condonería. En esta etapa es importante fomentar la expresión libre, creativa y respetuosa, en un ambiente cálido, y que el proceso sea de grupo. Se procurará que el nombre de la condonería evoque contenidos y referentes claros, y que el logo represente las perspectivas de trabajo y el respeto por la diversidad sexual. Para diseñar el folleto publicitario -que deberá tener información clara, que invite a los jóvenes a visitar la condonería y sentirse en confianza- es necesaria la participación del equipo para que aporte sus ideas y comentarios a los responsables de la producción. (La producción de materiales educativos es un proceso muy técnico que no se puede dejar en manos de jóvenes comprometidos pero inexpertos en el área de diseño.)

Como se indica anteriormente, es importante que la condonería tenga una sala de exhibición y un área para orientación-consejería; ambos sitios deberán ser adecuados a los objetivos lúdicos en el primer caso y de privacidad en el segundo. Debe promoverse el placer y la responsabilidad que dan libertad, con conocimiento, comodidad y seguridad.

Las personas que se hagan cargo de la condonería deberán cumplir algunos requisitos, como haber recibido el curso de sexualidad para docentes y un taller sobre vida erótica y 
protegida (ver capítulo Capacitación). Con esta capacitación se garantizará que conozcan el uso, las indicaciones y las ventajas de los anticonceptivos y otros productos que van a ofrecer. También les permitirá brindar orientación-consejería a individuos o parejas. Conviene elegir como mínimo a dos personas para asegurar la atención continua del lugar, de preferencia una joven y un joven. Sin embargo, quien se hará cargo de la administración es directamente la institución. Es recomendable que se hagan análisis de costos, gastos e ingresos de la condonería por lo menos cada tres meses, para revisar la situación financiera y las posibilidades de crecimiento y sostenimiento del negocio en el futuro.

Se ha observado que en la medida en que la condonería se ubique al interior de una clínica de salud sexual y reproductiva, pierde la identidad de un espacio abierto al público joven, por lo que se recomienda que se ubique en un local externo.

\section{Más ideas}

- Posicionar la condonería como un espacio de aprendizaje, educación, erotismo y protección, y promover la asistencia tanto de mujeres como de hombres jóvenes, pues la idea más generalizada es que estos establecimientos son un espacio exclusivo para varones, no necesariamente jóvenes.

- Promover las condonerías dando rienda suelta a la creatividad. Acudir a diversas propuestas, tales como hacer presencia en andenes de autobuses o del metro, en los mercados, en módulos de información, en clínicas; utilizar el perifoneo en la vía pública, ubicarse en las plazas y mencionarse durante la orientación-consejería personal, telefónica o vía Internet.

- Preguntar a los clientes cómo se enteraron de la condonería, qué despertó su interés por asistir a este establecimiento, qué esperaban encontrar y si satisfizo sus necesidades. Con ello, se sabrá cuál o cuáles estrategias de difusión fueron las más exitosas y si la condonería está cumpliendo con sus objetivos.

\section{Condonería móvil}

\section{Propósito de la actividad}

Acercar los materiales propios de la condonería a los lugares donde se reúnen los jóvenes.

\section{Cómo se realiza la actividad}

Se usa un maletín o zapatera plegable con secciones específicas para insertar los materiales de la condonería, tales como: condones de sabor, color, textura, aroma, figuras; lubricantes para condón y para masaje; Kleen Pack o Sex Pack; dildos, porta condones o condoneras, y otros productos eróticos y anticonceptivos. 
Las condonerías móviles son muy prácticas para los eventos masivos en la comunidad en donde se cuente con un puesto de promoción.

\section{Más ideas}

- Utilizar un cajón como condonería móvil y colocarlo en una bicicleta o en un coche, el cual se decora con condones y colores para que llame la atención.

- Llevar la condonería móvil a lugares en donde no permiten el acceso de estos productos por prejuicios o miedo. En este caso, las condonerías se guardan en mochilas y se trasladan a los eventos a los que los promotores acuden, en donde promueven y facilitan el acceso a los materiales, así como a la información y referencia a los servicios de salud sexual y reproductiva.

- Otra buena oportunidad para llevar la condonería móvil es al impartir el taller Vida erótica y protegida (ver capítulo Capacitación), pues éste tiene como objetivo promover el uso del condón y de otros artículos que protegen de infecciones durante el intercambio de fluidos, así como de aquellos que contribuyen con el erotismo de la relación.

\section{Otras actividades}

Los propósitos del componente comunitario pueden lograrse de muchas maneras, tales como: concursos literarios; concursos en donde para pasar de una meta a otra es necesario responder preguntas sobre temas afines al Programa; búsquedas de tesoros, o clases formales a agentes comunitarios.

Los interesados en llegar a la población juvenil deben buscar con los mismos jóvenes el desarrollo de estrategias innovadoras que permitan alcanzar estos objetivos.

\section{COMPONENTE ESCOLAR}

Este componente está orientado a capacitar al personal docente, principalmente a los profesores que tienen como responsabilidad impartir las materias relacionadas con las etapas de la adolescencia y la juventud, y con la sexualidad de los jóvenes.

La expectativa es que los profesores repliquen la capacitación con sus alumnos y se conviertan en "multiplicadores" de la educación sexual. 


\section{OBJETIVOS}

- Movilizar a las escuelas públicas y privadas establecidas en el área de influencia, cuya población se encuentre entre los 10 y 24 años de edad, con el fin de impulsar los programas de educación sexual y la promoción de servicios de salud sexual y reproductiva dentro de sus planteles.

- Llegar a todos los planteles escolares ubicados en el área de influencia en los que haya jóvenes de entre 10 y 24 años, mediante la capacitación de maestros, alumnos y/o padres de familia.

- Diseñar y aplicar modelos de capacitación e información específicos para satisfacer las necesidades tanto de los alumnos como de las madres y los padres de familia de cada escuela.

- Impartir cursos demostrativos de educación sexual a los directores y maestros para que conozcan los modelos de capacitación y educación del Programa, al igual que sus materiales educativos.

- Revisar y actualizar continuamente el listado de las instituciones educativas asentadas dentro del área de trabajo y hacer contacto con las autoridades correspondientes (preferentemente de escuelas públicas) para presentar el programa de educación para docentes y estudiantes.

\section{¿DÓNDE SE DESARROLLA?}

Se trabaja primordialmente en las escuelas ubicadas en el área de influencia, ya que en ellas se encuentra un alto porcentaje de los adolescentes y jóvenes.

En los planteles en donde no se pueda capacitar a los docentes, el Programa puede negociar con las autoridades escolares para dar directamente los cursos y pláticas a los alumnos y a los padres de familia. También se pueden vincular las actividades en las escuelas a instituciones gubernamentales que tienen programas dirigidos a jóvenes, por ejemplo, el instituto de la juventud local, proyectos productivos y proyectos de prevención de adicciones. Lo ideal es que las escuelas adopten el modelo de educación sexual y que los talleres se lleven a cabo año con año con el apoyo de su propio personal; en este caso, el Programa sólo contribuirá con el préstamo de materiales educativos o la invitación a participar en un taller de actualización al equipo docente. 


\section{OPERACIÓN}

\section{A. Selección de escuelas}

El Programa trata de llegar a todos los planteles escolares dentro del área de influencia, dando preferencia a las escuelas públicas por las características socioeconómicas de los jóvenes que ahí asisten.

Para identificar las escuelas ubicadas en la zona de influencia, se integra una lista de las primarias, secundarias, preparatorias e instituciones de educación superior, con base en el diagnóstico inicial. Posteriormente, lo aconsejable es hacer un contacto sistemático con cada institución; se puede acudir al Ministerio de Educación Pública local, que podría facilitar un directorio con los nombres de los directores y los domicilios de las escuelas.

Luego se prepara un escrito oficial, acompañado de los materiales que describen a la institución, su misión y visión, sus objetivos y los del Programa. La información incluida menciona los diferentes cursos de capacitación que se ofrecen y la gama de actividades que pueden realizar los alumnos. A las escuelas privadas se les agregará información sobre cuotas de recuperación de los cursos. Con las escuelas oficiales se puede negociar la venta de material educativo (folletos, libros, películas) a falta de una cuota específica.

Ya con el escrito oficial de la institución y los materiales listos, el coordinador juvenil y/o los funcionarios de la propia institución visitan las escuelas para presentar el Programa y negociar la implementación de capacitaciones.

Cuando las autoridades escolares dan su anuencia, se hace la programación de los cursos de capacitación que aceptaron. Aquellos para maestros debieran ser costeados por ellos mismos; las cuotas de recuperación se destinan para el pago de honorarios de ponentes y para cubrir los gastos de logística, además de que podrían generar ingresos para el Programa mismo. Evidentemente, si se obtiene el apoyo de algún donante para llevar a cabo esta actividad, el curso puede ofrecerse de forma gratuita, pero es importante dar a conocer el costo para que el personal docente lo aprecie. Si la institución se compromete con el Programa, se pueden otorgar becas de capacitación.

\section{B) Selección de maestros}

Por su autoridad, función y convivencia diaria, la mayoría de los jóvenes supone que los maestros pueden darles la información para satisfacer sus dudas sobre sexualidad y reproducción. Cuando un profesor o profesora no está capacitado o interesado en transmitir los conocimientos o aclarar dudas, la información que brinda es limitada y puede llegar a frustrar a los jóvenes, por lo que es muy importante seleccionar bien a los maestros que participen como "multiplicadores" del Programa. La labor del profesor es básicamente 
la de proporcionar de forma interactiva información científica, objetiva, libre de mitos, incluyente y sin discriminación, que se aplique a la realidad de los jóvenes, en el marco de sus derechos sexuales y reproductivos.

Para brindar la capacitación a los maestros se requiere de personal profesional que ha sido debidamente entrenado por la institución. Es necesario que los instructores hayan tomado un curso básico de sexualidad humana llamado Taller de Sexualidad (es) Bienestar, que tiene una duración de 40 horas (ver capítulo Capacitación). El Programa recomienda que otras instituciones den también una capacitación similar a los maestros multiplicadores. Dependiendo de los recursos con los que se cuente, una vez que termina la capacitación de los profesores se puede dotar a la escuela de un paquete de materiales educativos (que deberían obtenerse del acervo de la institución) que sirven a los maestros como apoyo metodológico para dar sus cursos (ver Apéndice 7).

El acompañamiento a la labor de los profesores capacitados es determinante para asegurar su permanencia en el Programa y cuidar que con el tiempo no se distorsionen los conceptos, creando mitos e información no verídica, sino que pongan en práctica los conocimientos recibidos durante su capacitación.

\section{C) Participación de madres y padres de familia}

Durante las visitas a las escuelas, es conveniente explorar la posibilidad de iniciar pláticas de sensibilización dirigidas a madres y padres de familia, mismas que podrían realizarse en las aulas como parte de las actividades escolares, como un apoyo dirigido a ellos (escuela para padres).

Las Encuestas Gente Joven 1999, 2002 y 2004 evidencian el deseo de los jóvenes y adolescentes de que sus padres tengan información suficiente sobre sexualidad y la disposición para abordar estos temas con ellos. Es importante mencionar que el personal del Programa puede impartir a los padres, con sus debidas adaptaciones, el mismo curso básico de sexualidad que se da a los maestros. Para este propósito, es útil recurrir a bibliografía especializada para padres y procesos de aprendizaje de las personas adultas.

\section{D) Intervención directa en las escuelas}

En aquellas escuelas en donde no sea posible capacitar a los profesores, el Programa (en particular, funcionarios de mayor jerarquía en la institución) puede negociar con la dirección del plantel la intervención directa con los alumnos. Se recomienda que en estos casos se inicie dando el ya mencionado Taller de Sexualidad (es) Bienestar para jóvenes, es decir, el que se imparte a los multiplicadores y tiene una duración de 40 horas. También pueden darse pláticas sobre temas de sexualidad, salud sexual y reproductiva, y otros afines, así como talleres, obras de teatro, concursos y exhibición de carteles sobre los mismos temas. 


\section{COMPONENTES DELLPROGRAMA JUVENII}

Se sugiere que siempre se programen con las autoridades escolares actos de apertura y cierre de la capacitación en los que participen el personal docente, el alumnado, y madres y padres de familia. Si los maestros fueron capacitados, durante la clausura se entrega a la dirección de la escuela un diploma que la acredite como capacitada por el Programa. Esta acreditación indica que dispone de personal capacitado y amigable con los jóvenes. La ceremonia de culminación de la capacitación representa una oportunidad adicional de promoción del Programa a un público más amplio. Como parte de la conclusión de la capacitación se pueden realizar actividades ya descritas en la sección sobre el componente comunitario y con contenidos relacionados con el Programa, tales como la representación de alguna obra de teatro, concursos de carteles o periódicos murales realizados por los jóvenes; la preparación de composiciones escritas; la composición y/o ejecución de una obra musical por la banda de guerra, la estudiantina escolar u otros grupos musicales de la escuela, o la realización de un encuentro deportivo. También puede aprovecharse el evento para convocar a los y las estudiantes a formar parte del Programa como promotores juveniles o a asistir a los "espacios amigables". Inclusive, muchas de estas actividades se pueden llevar a cabo en un contexto de competencia entre grupos de la misma escuela o con una perspectiva interescolar, presentando los mejores trabajos, organizando algún desfile informativo, un performance, una obra de teatro o una olimpiada de la sexualidad con los diferentes planteles participantes.

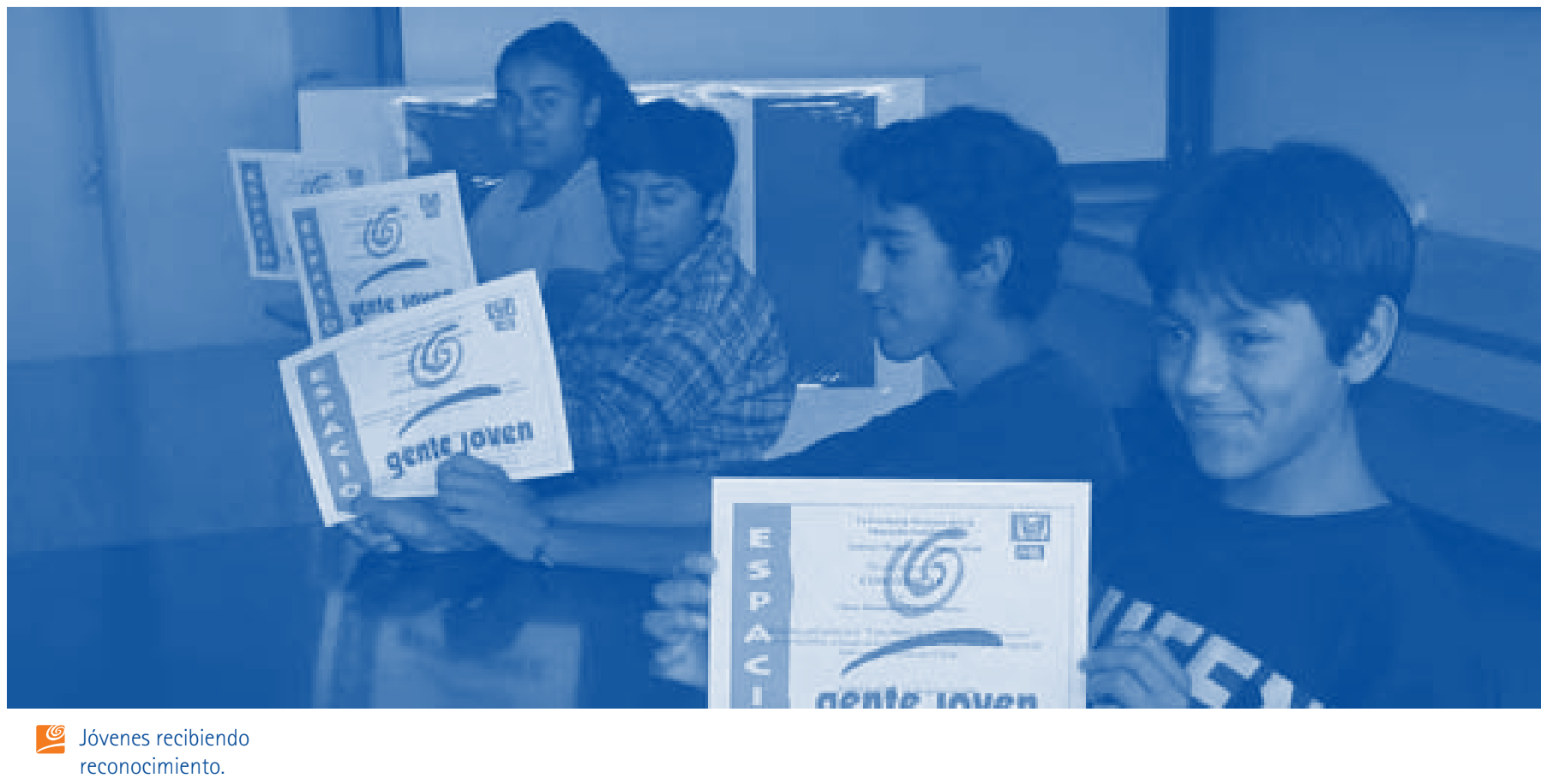


Lo ideal es que el Programa prepare a los grupos con el modelo de capacitación institucional y que cada año continúe esta labor con los nuevos grupos que se incorporan a 5 o de primaria y 1 을 de secundaria.

\section{E) Intervención indirecta en las escuelas: formación de maestros como multiplicadores}

Una parte importante de la estrategia escolar es que el personal del Programa no tenga que llevar a cabo las actividades de manera directa. Para esto, el trabajo de los maestros capacitados como multiplicadores es crucial. Al momento de negociarse la realización del curso para los maestros, el plantel y éstos deben comprometerse a:

- Replicar el curso con los alumnos, organizar actividades relacionadas con el curso y distribuir o vender, según el caso, los materiales educativos.

- Informar al coordinador del Programa, mes a mes, sobre las actividades que realicen, como pudieran ser: el número y tipo de cursos impartidos, el número de estudiantes que participaron en cada actividad, la colaboración que hayan prestado para labores especiales, incluyendo ferias de salud, actividades comunitarias, visitas para demostrar los resultados del Programa, sesiones de actualización, evaluación del Programa, adquisición de materiales, entre otras.

- Permitir que el Programa haga un seguimiento rutinario de las actividades.

El coordinador y/o los docentes que impartan los cursos deberán preparar una lista con sus nombres y características (edad, dirección y datos de contacto, estado civil, profesión, institución de pertenencia) para registrarlos como multiplicadores. El formato debe de tener espacio para incluir datos sobre el seguimiento de sus labores, lo que permitirá preparar listas actualizadas de multiplicadores activos y de sus actividades. El Programa puede hacer su propia definición de multiplicador activo. Puede considerarse activo, por ejemplo, a cualquiera que haya tomado el curso y hecho cuando menos una actividad para el programa en el último año.

Se entregará un diploma o constancia a los profesores que hayan cubierto el $80 \%$ de las asistencias y hayan aprobado las evaluaciones.

Para hacer las intervenciones indirectas, en lo posible, tendrían que cumplirse también otros requisitos, como por ejemplo:

- Hacer contacto con autoridades estatales o municipales de educación pública, así como de programas gubernamentales que se ocupen de jóvenes.

- Realizar la presentación de la institución, su Programa y los contenidos de capacitación para docentes y multiplicadores. (Ver capítulo Capacitación.) 
- Elaborar o poner en vigencia un convenio que otorgue validez oficial al curso de capacitación de los profesores.

- Convocar a una reunión regional de zonas escolares o direcciones escolares para presentar oficialmente el curso.

- Preparar la agenda de actividades del semestre o del año con cada director o directora de las escuelas involucradas.

- Hacer la presentación del programa de capacitación a profesores y acordar las fechas y horarios de los cursos.

- Recabar el acuerdo firmado por la autoridad escolar correspondiente.

\section{F) Evaluación de maestros multiplicadores}

La evaluación de la participación de los profesores como multiplicadores se puede hacer antes y después del curso.

Antes del curso. Aplicar un cuestionario que mida los conocimientos y actitudes de los profesores, con el objetivo de ajustar el curso a los requerimientos de los participantes.

Durante el curso. Se ofrecerá el Taller de Sexualidad (es) Bienestar y se utilizarán las publicaciones de la institución que se refieran a los temas del curso.

Después del curso. Al terminar el curso se aplicará a los participantes el mismo cuestionario para medir los conocimientos adquiridos y sus posibles cambios de actitudes comparándolos con el primer cuestionario. El coordinador hará el análisis de los resultados y elaborará un informe, incluyendo las bajas o deserciones, si las hubo, y las opiniones de los profesores.

Al término del curso y con los informes de evaluación de conocimientos y de actitudes, se retroalimentará a los maestros que participaron en la capacitación y se propondrá un programa de actualización y capacitación continuo.

\section{COMPONENTE DE SERVICIOS}

\section{MÉDICOS AMIGABLES}

Este componente incluye la capacitación de médicos y otros profesionales del área de la salud en la atención integral y amigable del adolescente.

Los servicios médicos amigables son aquellos brindados con calidad y comprensión a los jóvenes, sin juzgar ni criticar, respetando sus derechos sexuales y reproductivos, su derecho a la información y dándoles la importancia que cualquier persona merece. 


\section{OBJETIVOS}

- Lograr que los centros de salud o consultorios médicos del área de influencia ofrezcan servicios integrales y amigables de salud sexual y reproductiva a los adolescentes y jóvenes.

- Proporcionar atención amigable y confidencial para adolescentes y jóvenes. Dicho proceso está vinculado con otras instituciones del sector salud y de la sociedad civil organizada.

- Dar asistencia técnica y actualización continua al grupo de profesionales de la salud ya capacitados en atención amigable.

- Fomentar la creación de centros de servicios médicos especializados en la atención de jóvenes.

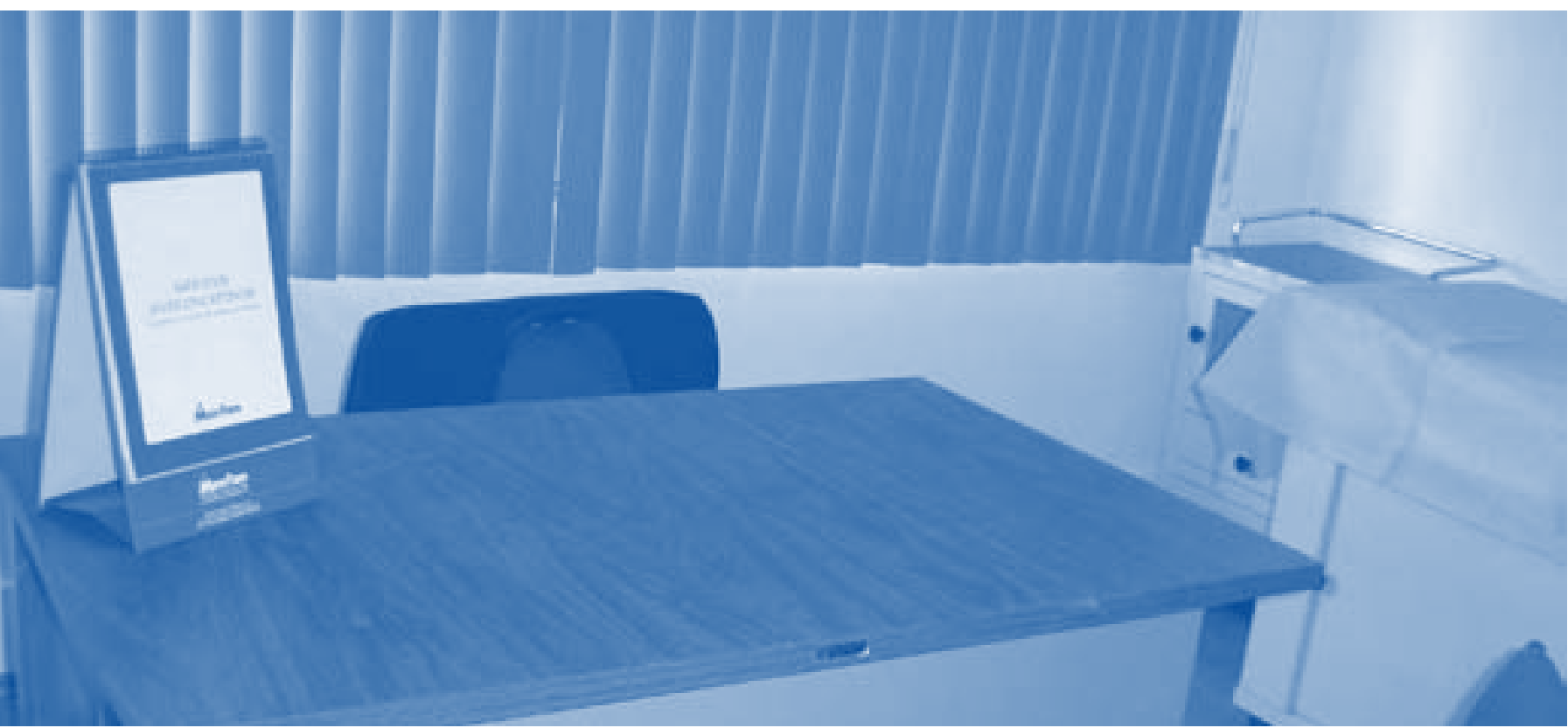

Consultorio médico integrado al Programa.

\section{¿DÓNDE SE DESARROLLA?}

En clínicas, centros de salud y servicios médicos de cualquier tipo o institución de salud que se encuentren dentro del área de influencia y que participen de esta estrategia. 


\section{OPERACIÓN}

A) Perfil

Los profesionales de la salud que formen parte de los servicios amigables deben tener las siguientes características:

- Demostrar interés por los jóvenes y prepararse para ofrecerles servicios de salud sexual y salud reproductiva.

- Mostrar su empatía con ellos y respetar sus derechos sexuales y reproductivos.

- Manifestar actitudes de compromiso.

- Respetar la intimidad de los jóvenes y la confidencialidad de sus problemas.

- En lo posible, estar capacitados para las consultas integrales.

- Tener o adquirir habilidades y disposición para la comunicación interpersonal y en especial con los adolescentes y jóvenes.

- Contar, en lo posible, con disposición para el trabajo comunitario y actividades fuera de la clínica y de los horarios institucionales.

\section{B) Capacitación}

Los proveedores de servicios amigables deben tomar una capacitación con contenidos en: sexualidad, atención integral, orientación-consejería, desarrollo durante la adolescencia y los principales problemas de salud que pueden presentarse en esta etapa.

En la capacitación se hace énfasis en factores de riesgo y prevención, así como en la atención con equidad, con perspectiva de género, sin discriminación e incluyente de la diversidad humana.

Debido a que las encuestas muestran que existe una demanda insatisfecha de servicios, se considera ideal que la clínica o centro de salud en cada área de trabajo cuente con al menos cinco profesionales de la salud capacitados mediante el Taller de Sexualidad (es) Bienestar y el curso Atención Integral del Adolescente (ver capítulo Capacitación).

\section{C) Desempeño de prestadores de servicios}

Los médicos son los prestadores de servicios de salud que más respeta la comunidad y en quienes recaen en gran medida los servicios amigables, por lo que se vuelve de vital importancia su participación en el Programa.

Sin embargo, otros profesionales de la salud con mayor estabilidad al interior de las instituciones son las enfermeras, los psicólogos y las trabajadoras sociales, quienes tienen el 
primer contacto con los jóvenes que acuden a los servicios médicos y se convierten en los primeros promotores, especialmente cuando se trata de dar orientación-consejería y entregar métodos anticonceptivos, por lo que es de vital importancia que también sean capacitados.

Algunas de las acciones que llevan a cabo estos prestadores de servicios son:

- Brindar información a la gente joven.

- Organizar grupos de enseñanza y autoayuda.

- Ofrecer cursos y pláticas en las unidades médicas o en la comunidad.

- Participar en la elaboración de materiales educativos para atender a la población que acude a los servicios.

- Apoyar en la creación de mejores estrategias y actividades de intervención, pues se destacan como orientadores y conocedores de las prácticas de salud comunitarias.

- Dada su permanencia en los programas, son excelentes aliados en el proceso de disminución de tiempos de espera, lo que mejora la calidad de la atención médica a los jóvenes.

\section{D) Actividades}

El personal capacitado por el Programa puede llevar a cabo todas las actividades que se mencionan a continuación en clínicas y servicios médicos de cualquier tipo o institución que participe conjuntamente en la estrategia de atención amigable a jóvenes:

- Atender de forma amigable a todo adolescente o joven de entre 10 y 24 años que acuda a los servicios de orientación-consejería en aspectos de salud sexual juvenil.

- Suministrar condones para prevenir tanto embarazos no planeados como infecciones de transmisión sexual, incluyendo el VIH.

- Proporcionar orientación-consejería en anticoncepción de emergencia y suministrarla en el momento necesario, así como otros métodos anticonceptivos.

- Llevar un registro mensual de las consultas, incluyendo los motivos que dieron lugar a ellas.

- Participar en visitas de supervisión del Programa y en los cursos de actualización.

- Tener disposición para organizar réplicas de cursos en su institución.

- Crear una red de referencia a servicios que la institución no tenga capacidad de ofrecer. 


\section{FARMACIAS AMIGAS}

De acuerdo con las encuestas Gente Joven de 1999, 2002 y 2004, más del 80\% de las y los adolescentes refirieron que su primera fuente para obtener pastillas y condones era la farmacia, por lo que la institución diseñó e implementó la estrategia de farmacias amigas.

\section{OBJETIVOS}

- Facilitar el acceso a los métodos anticonceptivos, sobre todo a los condones y a la anticoncepción de emergencia.

- Involucrar a farmaceutas, dueños o encargados de farmacias y empleados de mostrador en los propósitos del Programa.

- Invitarlos a brindar un trato amigable y sin juzgar a los adolescentes y jóvenes que soliciten condones o cualquier otro método anticonceptivo.

- Capacitar a los farmaceutas para que puedan proporcionar a los jóvenes información para el uso adecuado del condón, la anticoncepción de emergencia y otros métodos anticonceptivos.

\section{¿DÓNDE SE DESARROLLA?}

Como es fácil deducir, este componente se ejecuta en las farmacias del área de influencia del Programa que acepten participar en la estrategia. Para tener un panorama general de éstas, es conveniente ubicar a las asociaciones de farmaceutas y a sus representantes, pues esa vía es muy redituable para promover la estrategia de farmacias amigas, sus objetivos, los beneficios para la salud sexual y reproductiva de los jóvenes e inclusive para incrementar la clientela de la farmacia. Para tal efecto, hay que preparar la entrevista, proponer la capacitación a las personas que atienden el mostrador y hablar de productos novedosos, como la anticoncepción de emergencia, el condón femenino y métodos de reciente lanzamiento que pueden ser de particular interés para los dueños y responsables de las farmacias.

Una vez aceptada la propuesta por la asociación de farmaceutas, se visitan las farmacias en el área de influencia y se informa al dueño, gerente y/o encargado de las mismas sobre los objetivos del Programa.

Durante las visitas, se recomienda despejar todas las dudas que los farmaceutas pudieran tener respecto de su participación y dejarles información escrita sobre el Programa y la institución, así como sobre el papel de las farmacias amigas. 


\section{OPERACIÓN}

\section{A) Capacitación}

Generalmente se da un curso básico de sexualidad vía mostrador, ya que la experiencia ha demostrado que resulta difícil la capacitación en grupo de los farmaceutas. Por esta razón, la institución desarrolló en 1999 la estrategia de capacitación individualizada en mostrador y la provisión de materiales educativos y de apoyo al farmaceuta. Dado que esta capacitación se da en el mismo lugar de trabajo, los factores de tiempo, ausencias o desplazamientos no son un obstáculo.

En la capacitación a los farmaceutas se hace énfasis en temas como la anticoncepción de emergencia, el uso correcto de condones masculino y femenino, los derechos sexuales y reproductivos de la gente joven, así como los conceptos básicos de orientación-consejería en mostrador.

\section{B) Material de trabajo}

El paquete de materiales que la institución desarrolló para esta estrategia contiene lo siguiente:

- Carpeta con información básica sobre: métodos anticonceptivos modernos que pueden utilizar los jóvenes; derechos sexuales y reproductivos de los jóvenes, y conceptos básicos de orientación-consejería en mostrador.

- Un pequeño exhibidor con folletos que promuevan los diferentes temas de salud sexual y reproductiva.

- Carteles en forma de colgantes, calcomanías o en cualquier otra modalidad, según sea el caso, para que identifiquen el establecimiento como una farmacia amiga miembro del Programa. Los materiales que promueven los temas de salud deben ser de tamaño mediano para que no resten visibilidad a los otros productos de las farmacias.

Es importante que el farmaceuta cuente con un directorio de los servicios médicos amigables de la zona, así como páginas de Internet especializadas en salud sexual y reproductiva de la gente joven. Por ejemplo: www.gentejoven.org.mx y www.mexfam.org.mx.

\section{C) Actualización}

El coordinador o el promotor asignado para coordinar esta estrategia de farmacias amigas deberá tener en cuenta algunos problemas que se pueden presentar durante el seguimiento. Por ejemplo, existe una alta rotación del personal de mostrador en las farmacias y hay también diversos turnos, por lo que hay que trabajar constantemente en capacitación en mostrador y hacer el seguimiento. Los programas de capacitación con el personal de far- 


\section{COMPONENTES DELLROGRAMA JUVENII}

macias se pueden realizar también fuera de los horarios de trabajo, previo consentimiento de los empleados y en convenio con los dueños. Si se trata de una red de farmacias y se acuerda un horario y logística con los gerentes, se puede capacitar conjuntamente a todo su personal.

\section{D) Evaluación}

Para evaluar esta estrategia de capacitación, la institución desarrolló un sistema de medición pre y post-intervención que consta de una encuesta al farmaceuta sobre conocimientos de salud sexual y reproductiva de las y los jóvenes y sus actitudes o percepciones hacia ellos. El cuestionario se encuentra en el Apéndice 4 de este manual.

\section{E) Actividades conjuntas}

Una vez que las farmacias amigas están funcionando, se pueden organizar actividades conjuntas con la estrategia comunitaria. Por ejemplo, se podría convocar a un concurso tipo rally: en las farmacias pueden colocarse las claves y las preguntas, mientras que quienes estén encargados de la vinculación con el Programa pueden plantear las preguntas y realizar la puntuación.

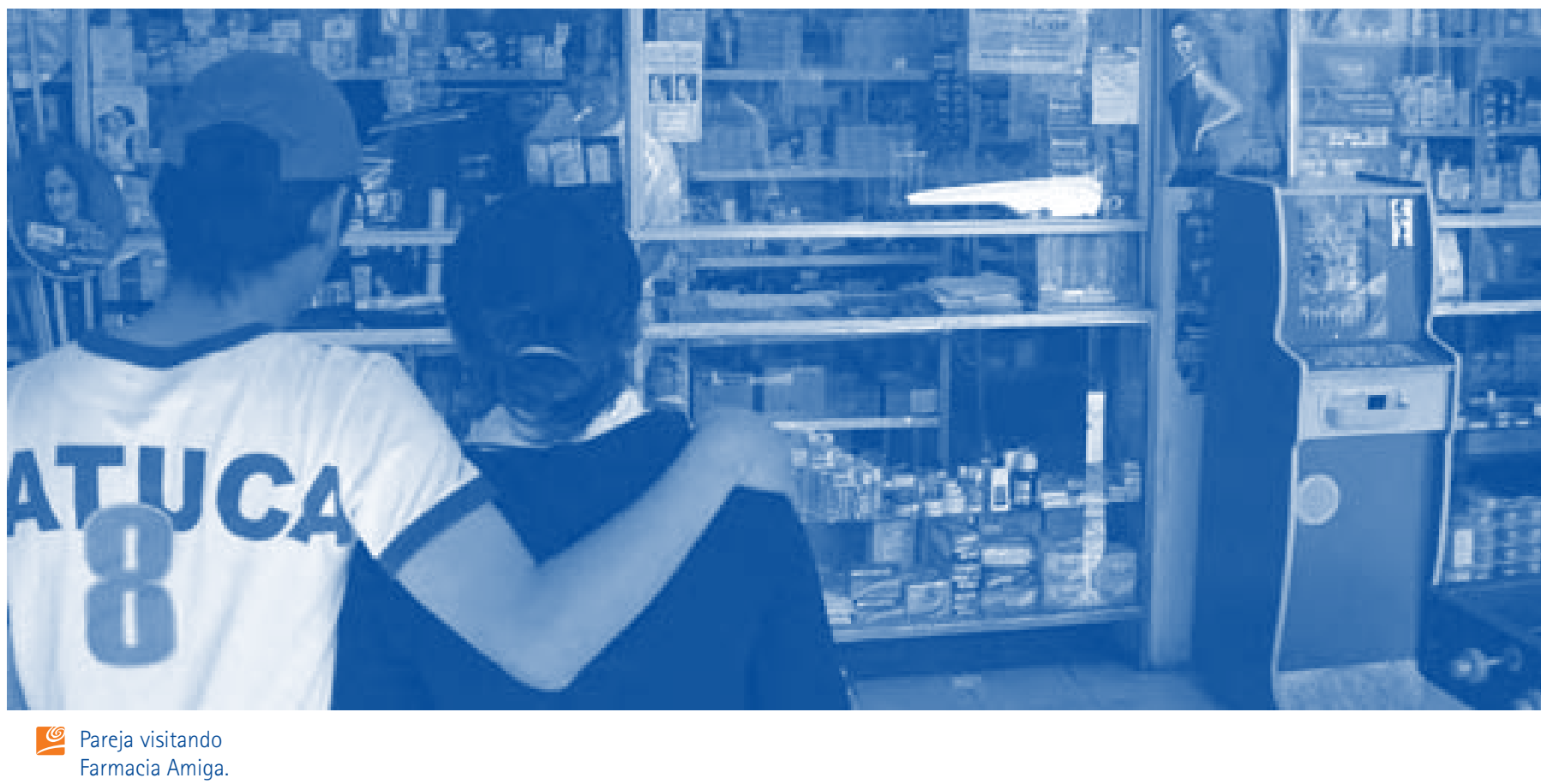


Los dueños de las farmacias podrían ser persuadidos de facilitar recursos tales como el sonido, los premios, la publicidad y otros, para el tipo de actividad que se lleve a cabo con la comunidad, lo que en última instancia les beneficia porque los jóvenes conocerán la ubicación de la farmacia para futuras necesidades.

\section{6}




\section{EL COORDINADOR Y LOS PROMOTORES JUVENILES}


En este capítulo ahondaremos en el perfil, la selección y las actividades de dos de los personajes claves para el funcionamiento exitoso del Programa: el coordinador juvenil y los promotores juveniles.

\section{COORDINADOR JUVENIL}

El coordinador será el encargado directo de la operación del Programa, es decir, la persona responsable de su funcionamiento en las áreas definidas para ello.

\section{PERFIL DEL COORDINADOR JUVENIL}

La selección del coordinador es responsabilidad del gerente local de la institución, con base en el perfil del puesto. Se trata de personas con las siguientes características, que trabajarán de forma asalariada.

- Hombre o mujer de 18 a 30 años.

- Estudiantes o recién egresados de alguna carrera, de preferencia en el área de humanidades, salud o educación.

- Sentido de servicio social en pro de los y las jóvenes.

- Disponibilidad de horario.

- Interés y/o experiencia en salud sexual y en aspectos relacionados a las necesidades de la gente joven.

- Compromiso social y con las causas juveniles.

- Tolerancia, respeto y actitud abierta ante las diversas expresiones sexuales y juveniles.

- Capacidad para entablar relaciones interpersonales.

- Habilidad para comunicar claramente sus ideas.

- Empatía con la gente joven.

- Creatividad e iniciativa para trabajar con adolescentes y jóvenes.

- Gusto por colaborar en equipos de trabajo y promover la participación juvenil.

\section{SELECCIÓN DEL COORDINADOR JUVENIL}

Para la selección, se pueden seguir los pasos que se indican a continuación:

\section{1) Convocatoria}

Se difunde a través de instituciones conocidas, de dirigentes comunitarios, anuncios en lugares públicos, bolsas de trabajo, preparatorias y universidades. En ocasiones hay que 
recurrir a anuncios en periódicos o revistas locales.

\section{2) Entrevista personal}

Se realiza con aquellos jóvenes interesados en el puesto, con el fin de seleccionar a la persona adecuada.

\section{3) Selección}

Si la persona entrevistada es la adecuada para el puesto, se le solicitarán los documentos que requiere el área de personal y se enviarán a las oficinas de recursos humanos o reclutamiento.

\section{4) Inducción}

Una vez firmado el contrato, y antes de que el coordinador empiece a desarrollar actividades, se le da un curso de inducción al puesto. La parte más importante de la inducción consiste en que el coordinador recién contratado pase un proceso de aprendizaje de dos semanas colaborando con un coordinador ya experimentado, para que aprenda en el campo los aspectos básicos de su actividad. Asimismo, debe ser capacitado lo antes posible en temas fundamentales de sexualidad y adolescencia.

\section{FUNCIONES DEL COORDINADOR JUVENIL}

Una vez que ha recibido la inducción al puesto, y si es un programa de recién apertura, el coordinador juvenil deberá:

- Establecer la zona de trabajo de acuerdo con las necesidades del Programa y/o de los proyectos.

- Elaborar un diagnóstico de la zona de trabajo.

- Hacer un inventario de recursos que incluya: a) lista de escuelas dentro del área de influencia clasificadas por nivel (primaria, secundaria, preparatoria o equivalente y universidades o equivalentes), por tipo (pública o privada) y con el total de maestros y estudiantes por grupo; b) lista de instituciones de salud por tipo (centro de servicios médicos, consultorio, hospital o clínica), si cuentan con servicios de salud reproductiva, programa de atención a jóvenes y personal que labora en ellas; c) lista de farmacias con el número de empleados en cada una de ellas; d) lista de programas y organizaciones que están trabajando en el área con jóvenes (con una breve descripción de los objetivos, las actividades y temáticas en las que intervienen, así como publicaciones que hayan hecho sobre el tema y la lista de sus materiales educativos).

- Identificar lugares de reunión de jóvenes en su área de trabajo, así como espacios de posible intervención, tales como clubes, fábricas, mercados, instituciones militares, es- 
taciones de policía, centros deportivos, canchas, espacios en instituciones afines, discotecas, teatros, cafeterías, bares, salones de baile y de fiestas, auditorios y centros de atención a bandas juveniles organizadas; así como organizaciones en las que hay jóvenes por diversas razones, como: orfanatos, casas hogar, centros de readaptación social o albergues.

Si es un programa con algún tiempo funcionando, deberá:

- Actualizar la lista de promotores juveniles del Programa e incluir datos que permitan evaluar su participación en el mismo.

- Realizar una guía para identificar multiplicadores activos y docentes capacitados en el área.

- Reconstruir la lista del personal de salud capacitado y entrenado en la atención integral y amigable de adolescentes y jóvenes.

- Elaborar registro cuidadoso de los docentes, personal de salud y de farmacias que se capacitan en las temáticas del Programa.

- Indicar el tipo de curso con el que se han capacitado y el registro de su participación mensual en las actividades del Programa.

Las actividades arriba enunciadas deben realizarse en colaboración con el coordinador saliente.

\section{Actividades de promoción y educación}

- Visitar las instituciones para presentar el Programa.

- Distribuir volantes y folletos durante eventos públicos y en visitas domiciliarias.

- Entregar o colocar carteles en las instituciones con las que se trabaja o se tiene afinidad.

- Coordinar o formar el grupo de promotores y sus actividades comunitarias.

- Crear y formar un grupo de docentes locales para el desarrollo de los cursos del Programa.

- Convocar a instituciones y personas a los cursos de capacitación del Programa.

- Ofrecer pláticas a líderes comunitarios, familias y profesionales interesados en la educación sexual de los jóvenes.

- Organizar a promotores en grupos musicales, de teatro o en equipos deportivos.

- Convocar y capacitar a los promotores como educadores de pares. 


\section{EL COORDINADOR Y LOS PROMOTORES JUVENILES}

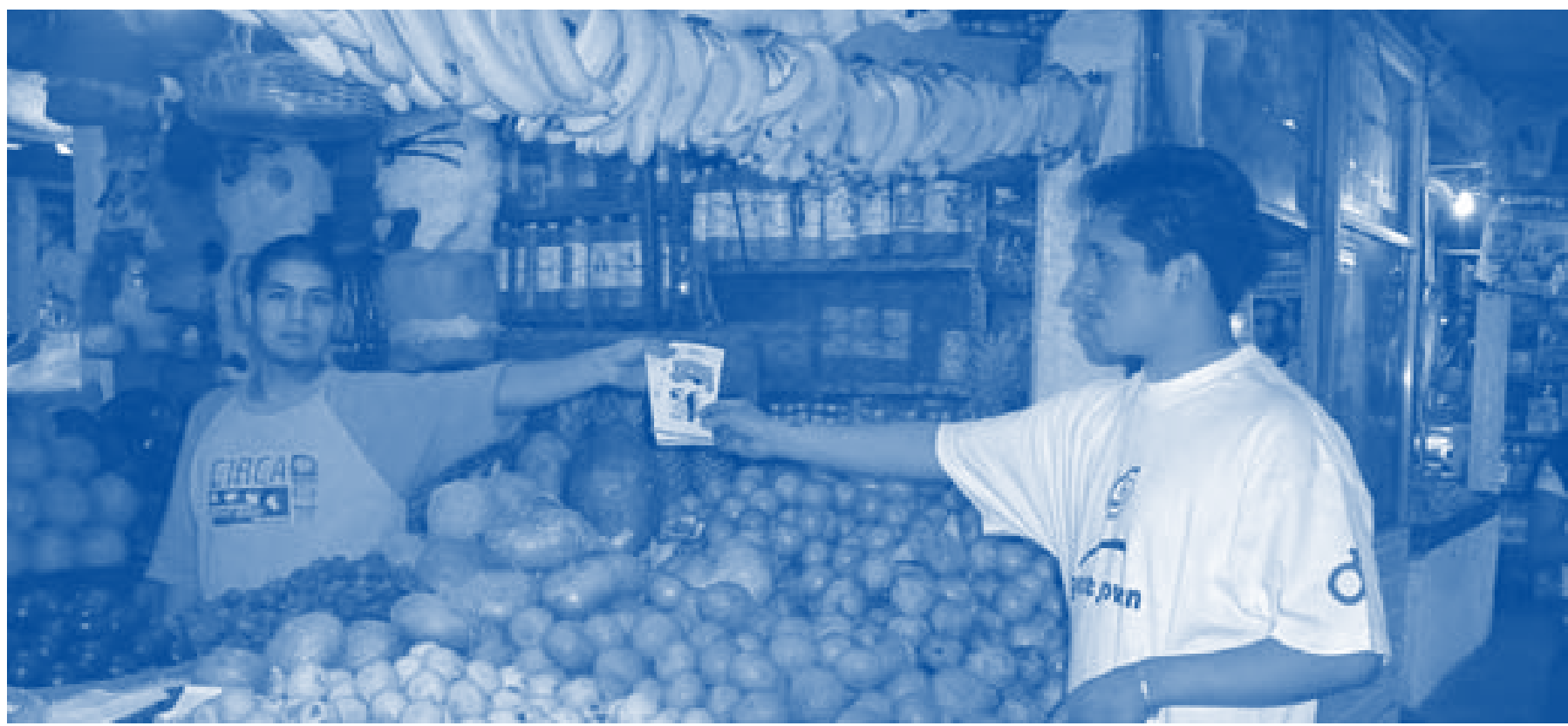

(G) Coordinador juvenil distribuyendo volantes.

\section{Actividades de planeación}

- Realizar cronogramas de actividades semanales, mensuales y anuales.

- Representar al Programa en las reuniones interinstitucionales y en las redes de trabajo dentro de su área de influencia.

- Contar con una agenda de trabajo interinstitucional, con la posibilidad de hacer algunas veces la convocatoria desde otros programas a las demás instituciones.

- Proponer actividades para conmemorar las fechas importantes de la salud sexual y la salud reproductiva. Se sugiere hacer una planeación anual, de tal manera que haya tiempo de organizar las actividades.

\section{Actividades políticas}

- Organizar y participar en ruedas de prensa, programas de televisión y eventos por la defensa de los derechos sexuales y los derechos reproductivos.

- Proponer nuevas legislaciones en materia de servicios y educación para jóvenes.

- Vigilancia ciudadana para el cumplimiento de los planes locales en materia de juventud.

- Participar en marchas relacionadas con los derechos sexuales y reproductivos. 


\section{Actividades administrativas}

- Elaborar y entregar un informe mensual de actividades, de acuerdo con los registros y los sistemas de evaluación entregados por la coordinación local.

- Elaborar un informe narrativo con el relato de sus actividades, ponderando logros, dificultades y alternativas de solución a los conflictos encontrados. Éste es un instrumento importante para la documentación de estrategias y eventos especiales.

- Distribuir y vender metodología anticonceptiva para jóvenes, especialmente condones como una medida de doble protección contra embarazos e Infecciones de Transmisión Sexual -incluido el VIH/SIDA-, así como anticoncepción de emergencia.

- Distribuir y vender material educativo.

\section{SUS RETOS}

Es posible que el coordinador juvenil experimente algunos contratiempos en su integración a las actividades del Programa:

a) Al enfrentar una nueva realidad y la existencia de jóvenes en condiciones de marginalidad social, política y económica, puede sentir impotencia e incertidumbre. De la manera en que resuelva este desafío dependerá su permanencia en el proyecto.

b) Cuando un coordinador empieza a vivir los problemas de la gente joven como propios, requerirá un periodo de adaptación para lograr una sana distancia que le permita trabajar objetivamente. Este momento es crítico, por lo que será fundamental el apoyo de un psicólogo que colabore en el Programa o de algún otro profesional, o la posibilidad de que el o la gerente local (o autoridad visible) mantenga conversaciones que le apoyen en ese proceso.

c) Hay un periodo durante el cual el coordinador podría tener problemas al enfrentar al público con el que trabaja como profesional de la educación. Es importante reforzar sus aptitudes docentes y proporcionarle asistencia técnica cuando sea necesario, con el propósito de que desarrolle las habilidades necesarias para que se desenvuelva adecuadamente en esas circunstancias.

d) Existe la tendencia entre los nuevos coordinadores a centrarse en las labores que más se les facilitan, por lo que es muy probable que en un inicio se enfoquen en las actividades del componente escolar. Será necesario estar insistiendo, persuadiendo y dando seguimiento para que los otros dos componentes, el comunitario y el de servicios, no sean descuidados. 


\section{PROMOTORES JUVENILES}

La participación voluntaria de jóvenes líderes es fundamental para el funcionamiento del Programa. El concepto de "voluntariado" en los jóvenes se ha convertido en un fenómeno mundial que surge de la determinación de este sector de la población de participar directamente en el desarrollo social y de manifestar su solidaridad y compromiso en actividades y objetivos concretos, respondiendo a su deseo de involucrarse activamente en los acontecimientos de la sociedad.

El trabajo voluntario da a los jóvenes una mayor autonomía y desarrollo personal, así como la oportunidad de manifestar su solidaridad. Los voluntarios se constituyen en excelentes voceros del Programa y de la institución, dado que se involucran y creen en sus causas y misión, además de que motivan al equipo de trabajo. De ahí la importancia y relevancia de su participación en las instituciones de la sociedad civil.

El modelo de participación de los voluntarios en el Programa debe incluir su capacitación en temas de salud sexual y reproductiva; el apoyo a otros jóvenes; la negociación, el liderazgo y la participación política; el uso de medios de comunicación y el seguimiento a discusiones en ruedas de prensa, radio y televisión que se relacionen con la salud sexual y reproductiva de la gente joven. Esta capacitación tiene como objetivo desarrollar las habilidades de los jóvenes para que participen en la elaboración de planes de trabajo y representen a sus compañeros y al Programa en sesiones y actividades públicas con poder de decisión y de voto dentro de la organización.

\section{SELECCIÓN DE LOS PROMOTORES JUVENILES}

Los promotores juveniles son la base y fortaleza para establecer y mantener el trabajo de un programa para jóvenes. Por eso es necesario identificar a promotores potenciales y asegurarse de que se trata de los idóneos. Los jóvenes que se identifiquen durante la etapa de planeación del Programa en las visitas domiciliarias, podrán ser un gran apoyo para identificar a otros jóvenes.

En el proceso de selección de los promotores juveniles es importante considerar tres etapas: 1) la convocatoria o invitación a la gente joven; 2) el reclutamiento, y 3) el diagnóstico de las necesidades de los promotores juveniles seleccionados.

\section{1) Convocatoria (actividad permanente en el Programa)}

La convocatoria debe invitar a los jóvenes a participar como promotores juveniles voluntarios, proporcionar información general acerca del Programa e introducir los temas de trabajo de tal forma que los jóvenes se sientan interesados y atraídos hacia las actividades que se organizan. 
La difusión debe realizarse a través de varios canales y no solamente por medio de un folleto o volante, pues de esta manera se evita que todos los voluntarios sean de un grupo específico de jóvenes. La promoción debe ser intensa y constante, siempre abierta para captar continuamente a nuevos candidatos que puedan apoyar al Programa, pues se ha observado que los promotores juveniles permanecen seis meses como promedio, hecho que hace necesario aprovechar cada oportunidad para reclutar nuevos integrantes.

Durante las invitaciones y entrevistas, es necesario transmitir claramente la misión del Programa y la importancia de la participación de los jóvenes para su funcionamiento, pues ello repercutirá en su confianza y seguridad hacia la institución donde van a desarrollar su trabajo.

\section{2) Reclutamiento}

Reclutar tiene que ver con comunicar e informar, y en este caso lo que se informa a un grupo de jóvenes interesados es en qué consiste el Programa y lo que se espera del trabajador voluntario, así como sobre la satisfacción que da el trabajo voluntario en beneficio de otros. El contenido debe ser claro y tener la información necesaria para que las personas que se interesen puedan comunicarse al lugar y con la persona indicada. Por ejemplo, la invitación debe mencionar:

- los objetivos y misión de la organización;

- lo que la organización requiere del voluntario;

- lo que la organización ofrece al voluntario (nuevas experiencias de aprendizaje y diversión al relacionarse con otros jóvenes);

- dónde y quién le va a entrevistar.

\section{A) Estrategias de reclutamiento}

Equipo de reclutamiento. La experiencia del Programa habla de que 90 por ciento de sus voluntarios son recomendados por voluntarios actuales o anteriores, de modo tal que los mejores reclutadores que puede tener un programa para gente joven son los mismos promotores juveniles del Programa. (Se deja abierto a la creatividad de los equipos la implementación de estrategias como el "Día del amigo del promotor", en el que los promotores llevan amigos a quienes se les presenta el Programa y se les invita a formar parte de él.)

Por lo tanto, es necesario integrar un equipo de promotores activos que pueden hacer la labor de difusión y la selección inicial de los nuevos promotores. Para reclutar a las personas idóneas, el equipo de reclutamiento debe definir las actividades en las que los voluntarios pueden participar y las expectativas que tiene el Programa de su trabajo y 


\section{EL COORDINADOR Y LOS PROMOTORES JUVENILES}

las de los voluntarios respecto al Programa. También debe establecerse cómo se hará la búsqueda de los posibles promotores y los recursos financieros existentes para cada actividad.

Diagnóstico inicial. La primera oportunidad para atraer voluntarios ocurre durante el diagnóstico del proyecto, cuando el coordinador puede invitar a los jóvenes a participar en el Programa como promotores juveniles voluntarios.

Lugares de reunión de jóvenes. Otra estrategia de reclutamiento consiste en visitar los sitios de reunión más comunes de los jóvenes-identificados en el diagnóstico inicial-y hacerles invitaciones formales a participar como promotores juveniles. También se les puede convocar para la organización de eventos escolares, comunitarios o cívicos en donde pueden conocer a otros jóvenes, y para que asistan a cursos sobre salud sexual juvenil.

Actividades del Programa. Durante las actividades educativas o comunitarias del Programa, se puede detectar a aquellos jóvenes que se destacan por su liderazgo, espontaneidad y deseos de participar y ayudar a los demás.

Medios impresos y electrónicos. Se pueden hacer invitaciones mediante anuncios en boletines, volantes, revistas, periódicos, o bien en folletos, trípticos o carteles diseñados para fines del reclutamiento. Igualmente se pueden aprovechar las páginas de Internet de la institución y del Programa. Se puede hacer un anuncio después de una charla, curso o evento y aprovechar la red interinstitucional. Cuando se usen estas estrategias, es conveniente probar el concepto, el diseño y los contenidos de los mensajes con grupos de jóvenes que tengan el perfil de los voluntarios y buscar apoyos financieros de empresas particulares, de instituciones del sector público o de los propios medios de comunicación para que la difusión de los mensajes sea gratuita.

\section{B) Perfil del promotor juvenil}

Aun reconociendo que no existe un promotor juvenil perfecto o modelo, se ha definido un perfil de los promotores, que ayuda a identificar y seleccionar a los jóvenes.

Se recomienda que el promotor juvenil tenga las siguientes características:

- Rango de edad: 12 a 24 años.

- Disposición para trabajar de manera voluntaria.

- Interés por aprender y capacitarse en temas de salud sexual y reproductiva.

- Compromiso para generar cambios en su entorno y por transmitir el conocimiento. 
- Interés en participar de manera activa en un programa juvenil para responder a las necesidades de la comunidad.

- Gusto por conocer nuevas personas.

- Disposición para realizar el trabajo comunitario en los tiempos en que la propia comunidad establezca.

- Entusiasmo, respeto y un amplio criterio para aceptar opiniones diferentes.

- Habilidad para establecer buenas relaciones.

- Capacidad de manejo de información relativa a los componentes del Programa.

- Habilidades de liderazgo o disposición para desarrollarlas.

- Dinamismo y confiabilidad.

- Habilidades o disposición para trabajar en equipo.

\section{C) Expectativas del Programa y de los voluntarios}

Es conveniente que el equipo de reclutamiento aclare las expectativas que el Programa tiene del trabajo de los promotores, así como aquellas que los voluntarios tengan respecto al Programa: lo que les atrae del trabajo voluntario, lo que les gustaría aportar, las áreas que más les interesan y si hay cosas con las que no estén de acuerdo.

Las expectativas del Programa incluyen que los voluntarios:

- Se capaciten y manejen los temas que desarrolla el Programa.

- Realicen las actividades planeadas y tengan siempre en mente la misión de la institución y promuevan sus objetivos.

- Muestren la seriedad y el compromiso de su trabajo, manteniendo conductas consistentes con el compromiso de la institución con la salud sexual y reproductiva de los jóvenes.

- Observen y apliquen las normas institucionales y los lineamientos internos de los espacios dedicados al Programa, para asegurar el bienestar de todos y ganar el respeto mutuo de los participantes.

- Contribuyan a mantener en orden y limpio el espacio juvenil.

- Se responsabilicen por el cuidado del espacio o de la clínica y del material educativo y anticonceptivo.

- Ofrezcan un trato cordial y amigable a las y los usuarios de los servicios. 
- Establezcan y cumplan con los acuerdos de convivencia con el coordinador en los espacios dedicados al Programa.

Aunque cada voluntario tiene sus propias expectativas, las que tienen los promotores juveniles del Programa frecuentemente incluyen:

- Pertenecer a un espacio o grupo juvenil con el respaldo de una institución, en donde los derechos de los jóvenes se respetan, es posible expresar ideas y éstas son tomadas en cuenta o discutidas de manera respetuosa.

- Contar con un espacio para divertirse, crecer emocional e intelectualmente y donde se les ponga atención, se les respete como personas con sus propios valores y no haya autoritarismo.

- Tener la posibilidad de adquirir una formación profesional y de asistir a cursos, talleres, pláticas y capacitaciones varias.

- Poder influir en la generación de cambios en el entorno social.

- Realizar actividades significativas en el nivel comunitario, gratificantes, tangibles e inmediatas para las personas que lo necesitan; hacer la diferencia y ver el fruto de sus esfuerzos.

- Establecer nuevos contactos y amistades con jóvenes que pertenecen a otras redes sociales.

- Disponer de apoyos económicos, por ejemplo, para transportarse de una comunidad a otra, para refrigerios durante las jornadas de trabajo comunitario, gorras para protegerse del sol durante las brigadas y mochilas para cargar los materiales y productos. Esta cuestión debe tenerse en cuenta al hacer los presupuestos.

El responsable del Programa debe conocer las expectativas de cada joven y tomarlas en cuenta para mantener su interés y apoyar su crecimiento personal, así como para poder aclarar aquellas expectativas que el Programa no podrá cumplir. Dependiendo del desarrollo de sus habilidades y de las situaciones locales, los voluntarios pueden convertirse en coordinadores juveniles (personal pagado), pero no es un compromiso institucional.

\section{3) Diagnóstico de las necesidades de los promotores seleccionados}

Este punto se relaciona directamente con las expectativas de los voluntarios que planteamos anteriormente y derivará en las actividades que realice el promotor. Para un programa juvenil debe ser de vital importancia que los jóvenes desarrollen su máximo potencial y liderazgo. Para que ello ocurra, se exploran las necesidades, las expectativas y los intereses de los promotores, y se busca dirigirlos hacia aquellas actividades en las que, en virtud de sus conocimientos y habilidades, puedan desempeñarse mejor. 


\section{ACTIVIDADES DE LOS PROMOTORES JUVENILES}

En realidad, no existen límites al tipo de trabajo que un promotor juvenil puede llevar a cabo. Según sus habilidades y liderazgo, los promotores pueden volverse buenos orientadores y consejeros; participar en el diseño y planeación de los programas, campañas y actividades comunitarias; colaborar con otras instituciones, o incluso hacer labores de evaluación y administración. Esto no implica que todos los promotores juveniles pasen por todas las tareas, sino que se especialicen de acuerdo a sus capacidades e intereses.

Un promotor juvenil ubicado en el lugar apropiado se comprometerá más con sus tareas y se sentirá más satisfecho realizando una buena contribución a la sociedad a través del Programa. Algunas de las actividades más comunes que llevan a cabo los promotores juveniles son las siguientes:

Promoción y difusión. Estas actividades consisten en difundir y promover el apoyo que ofrecen las clínicas para jóvenes, así como las actividades de los espacios propios del Programa y de las farmacias amigas ubicadas en la zona. Los promotores juveniles distribuyen folletos, carteles, volantes y trípticos con información sobre el Programa y los temas principales que se abordan en él. También organizan campañas de salud comunitaria y proponen nuevas actividades. Dentro de la capacitación que reciben, desarrollan habilidades en orientaciónconsejería, en salud sexual y reproductiva y en trabajo con grupos.

Distribución de métodos anticonceptivos. Otra actividad muy importante de los promotores juveniles es la distribución de métodos anticonceptivos, especialmente condones y anticoncepción de emergencia, indispensables en la prevención de ITS, incluyendo el VIH/ SIDA, y de embarazos no deseados o no planeados.

Educación e información. El promotor juvenil organiza cursos, talleres y pláticas en escuelas o en lugares en donde los jóvenes se reúnen. Otras actividades de este tipo comprenden módulos de información, brigadas de salud, grupos de trabajo comunitarios, ferias informativas de salud y funciones de teatro. El promotor puede contribuir a conseguir recursos financieros o patrocinios, y apoyar la organización y la logística de los eventos.

Es importante tener en mente a las madres y los padres de familia de los promotores juveniles, especialmente de los menores de edad. En este caso, se recomienda sean notificados e invitados a participar, si lo desean, para evitar conflictos familiares, aunque por experiencia se sabe que una vez que los padres conocen el Programa y asisten a algunas actividades, se gana su confianza y credibilidad permitiendo la continua participación de los adolescentes. 


\section{EDUCACIÓN ENTRE PARES: LA RECETA SECRETA}

Una de las principales bases de los programas juveniles es la educación entre pares, pues la experiencia ha confirmado que son los mismos jóvenes, capacitados y acompañados, los que deben atender a otros jóvenes como ellos. Pares son las personas que comparten la edad, los intereses, el lenguaje, el uso del tiempo y las aspiraciones. Son los amigos, compañeros y vecinos; son los jóvenes que poseen características y antecedentes similares a los del promotor juvenil. Puede decirse, en términos generales, que los jóvenes se relacionan mejor y tienen mayor confianza con quienes son similares a ellos; por lo demás, la evidencia muestra que la información que manejan los jóvenes sobre sexualidad la recibieron, en buena parte, de sus pares, por lo que es muy importante que éstos sean personas capacitadas en dichos temas.

Los promotores juveniles, independientemente de que sean profesionistas o estudiantes, tienen que recibir una capacitación especial que les permitirá apoyar a los jóvenes con información y servicios. Al participar de manera activa en el Programa, logran reconocimiento social en su comunidad, entre amigos, vecinos, compañeros de escuela y familiares, quienes los suelen reconocer como los que saben. Cuando ayudan a otros, tienen un sentido de pertenencia y credibilidad en sí mismos y en el Programa. Este rol les permite incrementar sus relaciones interpersonales y sus oportunidades de crecimiento. La gratificación social que reciben de manera casi inmediata por parte de la comunidad, los motiva y hace que se sientan reconocidos y valorados en su trabajo voluntario, y que reafirmen el compromiso social adquirido con sus pares y con otras personas que acuden al Programa.

\section{MISIÓN DEL VOLUNTARIO}

\section{El tiempo del voluntario es "tiempo libre que no está libre de compromiso"}

Uno de los hallazgos de la investigación "What young people want from volunteering"1 [Lo que los jóvenes desean del voluntariado], es que los jóvenes reconocen las ventajas que pueden tener cuando se ofrecen para trabajar como voluntarios. A partir de este estudio, se acuña el término "Flexivol", que resulta de unir las letras iniciales de ocho palabras en inglés que definen las características esenciales que hacen atractivo el trabajo voluntario de los jóvenes de 16 a 24 años de edad y que se recomienda que cumplan todos los programas juveniles:

1 Gaskin, Katheryn. 2000. Canadá. "What young people want from volunteering”, en Volunteer Connections: New Strategies for Involving Youth. p. 4. 
Flexibility $=\quad$ flexibilidad, en términos de los horarios y tiempo dedicado al Programa.

Legitimacy $=\quad$ legitimidad, en términos de que se da el mismo valor a su trabajo que al trabajo pagado, y que las instituciones con las que tienen contacto reconocen este hecho.

Ease of access = accesible, en cuanto a que se usa un lenguaje sencillo y se dan explicaciones que resultan claras.

'xperience $=\quad$ experiencia, en términos de que la pertenencia del Programa se convierte en una actividad formativa de la que aprenden técnicas y valores que pueden usar posteriormente en su vida personal y laboral.

Incentives $=\quad$ incentivos, que pueden ser: actividades de desarrollo personal; participación en reuniones y cursos con jóvenes de otras localidades; cartas de recomendación y constancias que pueden ayudarlos a obtener oportunidades laborales más adelante; becas que les permiten participar y ampliar las experiencias; objetos (como camisetas y gorras) que los identifican; monetarios para transporte y refrigerios; acceso a recursos, como bicicletas y otro tipo de equipo.

Variety = variedad, en cuanto a las actividades que se desarrollan, lo que permite mantener el interés en ellas.

Organization $=$ organización, en términos de que existen líneas claras de comunicación y acción con los promotores en el nivel local, y saben cómo es su relación con la institución. La supervisión es un acompañamiento en su trabajo, lo que los motiva más y amplían su sentido de pertenencia a un grupo y a una organización.

Laughs $=\quad$ risas, que significa realizar el trabajo de manera amena y divertida, pero no exenta de responsabilidad. 


\section{CAPACITACIÓN}


La capacitación representa una herramienta muy valiosa para el Programa, en tanto que contribuye a hacer realidad la misión y visión de la institución, así como a difundir la nueva cultura de la salud sexual, misma que incluye la promoción de la equidad de género, la participación de los hombres jóvenes y la defensa de los derechos sexuales y reproductivos. Como proceso de aprendizaje, la capacitación es un instrumento que empodera al individuo.

Mediante la capacitación se pretende, por un lado, fortalecer al personal institucional y, por el otro, llegar a la población adolescente.

Entre las metas que se busca alcanzar respecto al personal institucional podemos citar:

- Equipar a la gente joven de la institución con los conocimientos, las destrezas y la motivación que se requieren para realizar actividades de información y educación.

- Crear identidad y sentimiento de pertenencia entre el personal involucrado directa o indirectamente en el Programa, transmitiendo el anhelo de trabajar en una misma línea de manera eficiente.

En tanto, para la población adolescente se pretende:

- Proveerlos de los elementos, las habilidades y actitudes que les permitan tomar decisiones, incrementar su autoestima y ejercer su sexualidad de manera responsable.

- Fomentar el intercambio de experiencias, vivencias y conocimientos.

- Formar redes de personas capacitadas en la salud sexual y reproductiva de la gente joven.

Cabe mencionar que todas las actividades educativas están enmarcadas en el respeto a los derechos sexuales y reproductivos de las y los adolescentes.

\section{Momentos de la capacitación}

Los programas de capacitación al personal se dan en tres momentos: a) inicial o de inducción; b) capacitación general; c) de acompañamiento (durante el servicio), y d) de actualización.

\section{a) Talleres de inducción al puesto}

Estos talleres tienen como finalidad ofrecer al participante una visión general de la institución, del Programa juvenil y de las funciones que va a desempeñar, así como de sus obligaciones. 


\section{CAPACITACIÓN}

\section{b) Capacitación general}

La mayoría de los participantes son instruidos en temas importantes para el desarrollo de su función. El coordinador nacional recibe capacitación sobre abogacía (advocacy), autogestión de recursos, culturas juveniles, liderazgo y salud reproductiva; los voluntarios juveniles, sobre abogacía (advocacy), liderazgo juvenil y derechos sexuales y reproductivos; en tanto, los farmaceutas reciben capacitación en mostrador acerca de la misión y los objetivos del Programa, los derechos sexuales y reproductivos de los jóvenes, los métodos anticonceptivos, el uso correcto del condón femenino y masculino, la anticoncepción de emergencia y los beneficios de participar en el Programa.

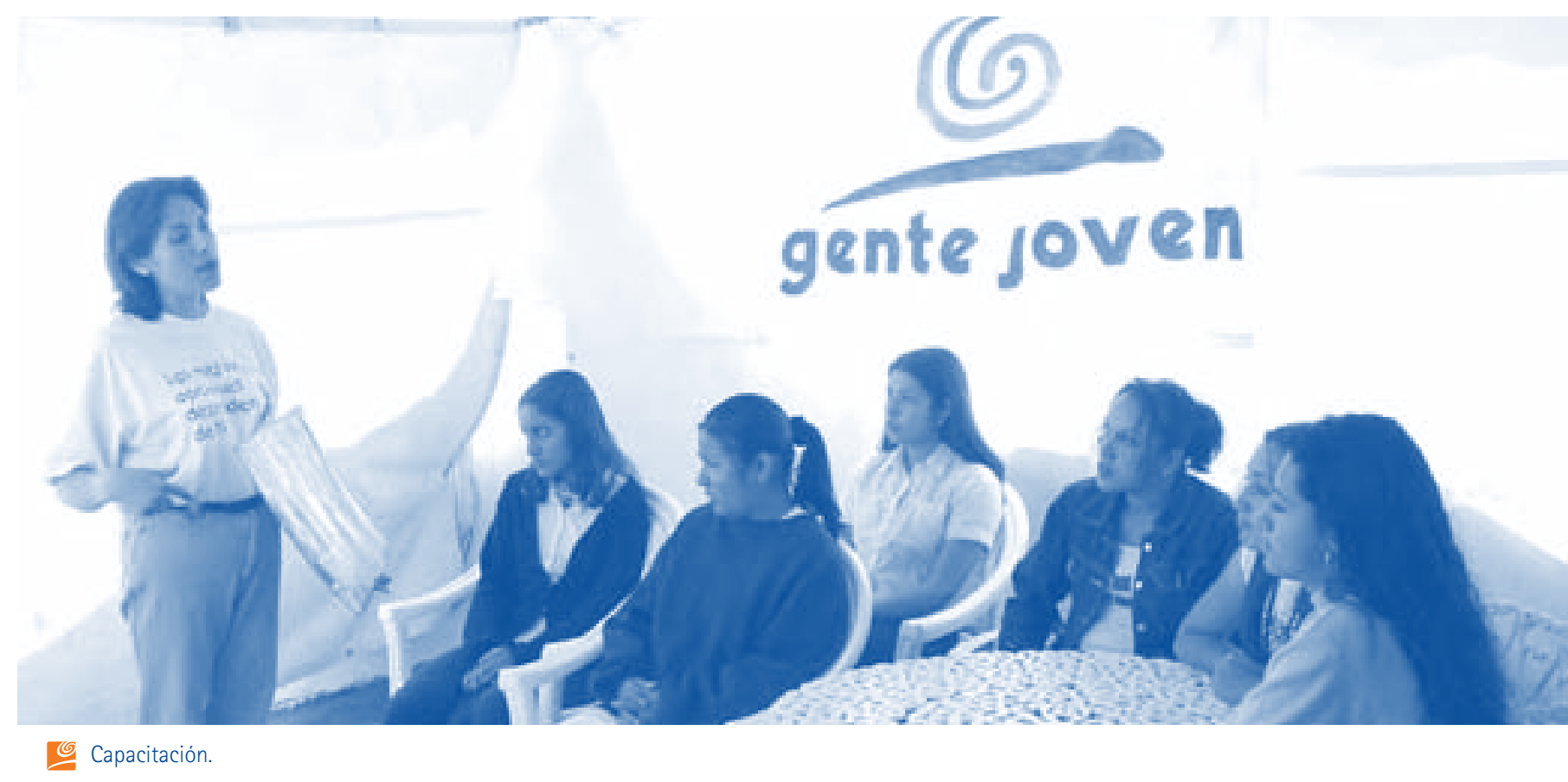




\section{c) Capacitación de acompañamiento}

Se acompañará a cada promotor juvenil durante la realización de sus actividades con el fin de que se sientan apoyados, pues aunque cuenten con los conocimientos necesarios, muchas veces, al iniciar el trabajo en campo, pueden surgir situaciones en las que requieran apoyo de su coordinador o de algún promotor con más experiencia. Se le puede acompañar a impartir una plática o un taller; a gestionar algún evento o donativo, así como en la instalación de un módulo de información o en la organización de las brigadas comunitarias.

\section{d) Actualización y asesoría continuas}

Esta asesoría se caracteriza por ser flexible y con base en las necesidades y características de los promotores y/o coordinadores. Puede ser individual o en grupo. Igualmente, puede recurrirse a la actualización por correspondencia a través de boletines, artículos y otras publicaciones cuya información se juzgue de utilidad para la persona y el Programa.

\section{Características de las actividades de capacitación}

Contenidos flexibles. Los contenidos se adaptan de acuerdo a los objetivos del programa juvenil, a las necesidades de los participantes, a los requerimientos locales y a las situaciones sociales y políticas del momento.

Coordinación adaptable. Las capacitaciones se pueden coordinar tanto en el nivel central como en el local, dependiendo de las necesidades propias de las temáticas y de los proyectos específicos.

Correlación. Existen actividades de capacitación propias de cada componente del programa -comunitario, escolar y de servicios médicos-. Dependiendo del componente y de los participantes, es el tipo de capacitación que se imparte.

\section{¿Quién imparte los cursos?}

Los cursos son impartidos por personal institucional capacitado, que se ha desarrollado dentro del Programa y cuenta con la experiencia suficiente, o bien por colaboradores voluntarios o externos involucrados en los temas, y con la adecuada capacidad técnica y teórica para estar frente a grupos de aprendizaje. 


\section{CAPACITACIÓN}

\section{¿Qué capacitación adquirir?}

A continuación se muestra una tabla que incluye las diferentes capacitaciones que imparte la institución y las personas que deben tomarlas.

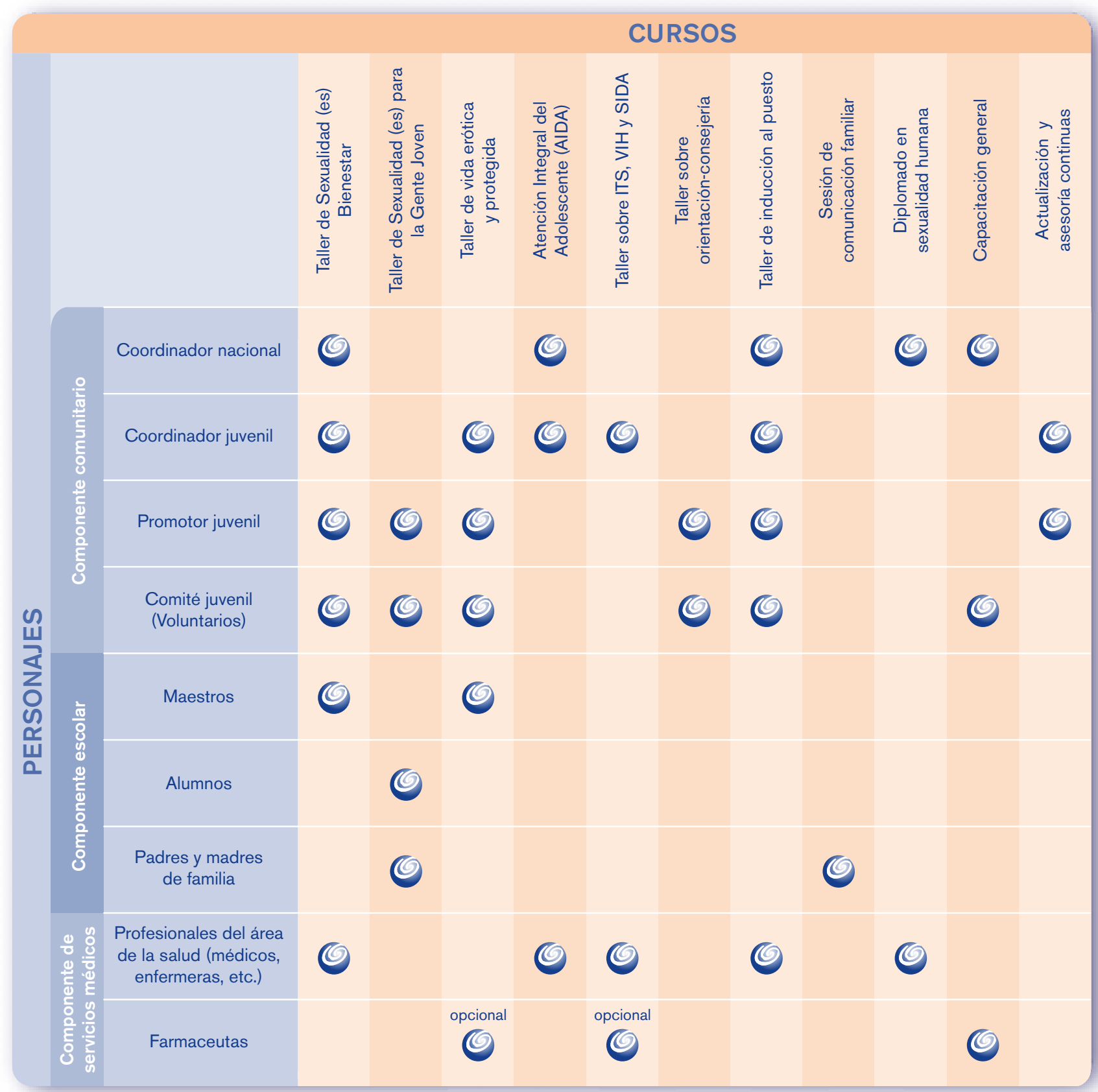




\section{El abc de la capacitación}

\section{TALLER DE SEXUALIDAD (ES) BIENESTAR}

\section{OBJETIVOS:}

- Brindar los elementos indispensables para mejorar la salud sexual del ser humano.

- Ofrecer bases que permitan mejorar la labor educativa y de orientación hacia los adolescentes.

- Promover entre la población juvenil la toma de decisiones responsables e informadas respecto a su salud sexual y reproductiva.

\section{DURACIÓN:}

40 horas

\section{TEMAS:}

- Conceptos básicos en sexualidad

- Comunicación familiar y sexualidad

- Derechos sexuales

- Desarrollo psicosexual infantil

- Pubertad

- Desarrollo psicosexual en la adolescencia

- Valores y sexualidad

- Respuesta sexual humana y expresiones del comportamiento

- Diversidad sexual

- Embarazo, parto y puerperio

- Embarazo adolescente

- Metodología anticonceptiva

- Infecciones de transmisión sexual

- VIH y SIDA

- Vida erótica y protegida

- Sexualidad y género

\section{6}


- Masculinidad y perspectiva de género

- Violencia basada en género

- Abuso sexual

- Actitud del personal docente ante la sexualidad y su papel como orientador

\section{METODOLOGÍA:}

Explorar mediante ejercicios vivenciales, debates y dramatizaciones una propuesta educativa de la sexualidad basada en información sencilla, clara y desmitificada, con el fin de formar educadores y orientadores sexuales de adolescentes y jóvenes.

\section{TALLER DE SEXUALIDAD (ES) PARA LA GENTE JOVEN}

\section{OBJETIVOS:}

- Identificar la importancia de disfrutar de una vida sexual satisfactoria, sin riesgo de contraer Infecciones de Transmisión Sexual o VIH, y que no esté encaminada únicamente a la reproducción.

- Identificar los conceptos básicos de salud sexual, sexualidad y salud reproductiva.

- Contar con los conocimientos y las herramientas necesarias para tomar decisiones informadas, responsables y libres, respecto al ejercicio de la sexualidad.

- Reconocer que la sexualidad se desarrolla en un marco de comunicación, convivencia y amor entre la pareja.

\section{DURACIÓN:}

14 horas, repartidas en 7 sesiones

\section{TEMAS:}

- Comunicación familiar

- Pubertad y proceso reproductivo

- Embarazo adolescente y anticoncepción

- El VIH/SIDA y otras Infecciones de Transmisión Sexual (ITS)

- Sexualidad y juventud

- Género

- Violencia basada en género

- Derechos sexuales y reproductivos 


\section{METODOLOGÍA:}

Espacio de reflexión, construcción y participación en donde se da el intercambio de experiencias entre los jóvenes a través de ejercicios vivenciales, debates y dramatizaciones que les ayuden a sensibilizarse sobre algunos aspectos de la sexualidad, así como a conocer determinadas habilidades psicosociales que les permitan ejercer sus derechos sexuales y reproductivos de manera más libre y responsable.

\section{SESIÓN DE COMUNICACIÓN FAMILIAR}

Antes de empezar con las sesiones del Taller de Sexualidad (es) para la gente joven, se da una plática de sensibilización a padres y madres de familia.

\section{OBJETIVO:}

- Mejorar la comunicación entre madres, padres, e hijas/hijos.

\section{DURACIÓN:}

2 horas

\section{TEMAS:}

- Familia y comunicación

- La comunicación durante la adolescencia

- Líneas de acción para mejorar la comunicación

\section{TALLER DE VIDA ERÓTICA Y PROTEGIDA}

\section{OBJETIVOS:}

- Identificar a las prácticas de sexo seguro y protegido como una alternativa para tener una vida erótico sexual más placentera y con el mínimo riesgo de adquirir una ITS, incluido el VIH/SIDA.

- Erotizar el condón, desgenitalizando el contacto sexual.

\section{DURACIÓN:}

8 horas

\section{TEMAS:}

- Anatomía de los órganos sexuales de la mujer y del hombre

- Diferencias entre sexo seguro y sexo protegido

- Características del sexo seguro 
- Características del sexo protegido; contacto pene-ano, pene-boca, pene-vagina

- Mitos y realidades del uso del condón

- Uso correcto del condón masculino y femenino, así como de Kleen Pack y lubricantes

- Vida erótica

- Anticoncepción de emergencia

\section{METODOLOGÍA:}

Explorar mediante ejercicios vivenciales, debates y dramatizaciones una propuesta educativa que permita fomentar la erotización del condón y la desgenitalización de las personas.

\section{ATENCIÓN INTEGRAL DEL ADOLESCENTE (AIDA)}

\section{OBJETIVOS:}

- Reconocer la importancia de proporcionar una atención integral y diferenciada al adolescente.

- Identificar los aspectos teóricos y técnicos para brindar servicios integrales y amigables a los adolescentes.

\section{DURACIÓN:}

32 horas

\section{TEMAS:}

\section{Salud integral del adolescente}

- Salud integral del adolescente

- Medicina del adolescente

- Servicios amigables

- Características del consultorio amigable

- Entrevista e historia clínica

\section{Salud física}

- Crecimiento y desarrollo del adolescente

- Tablas de crecimiento y desarrollo

- Higiene de la pubertad

- Estadios de Tanner 
- Alteraciones de la menstruación

- Patologías de los órganos sexuales masculinos

Salud mental

- Desarrollo psicológico del adolescente

- Desarrollo psicosexual e identidad sexual

- Factores protectores y habilidades para la vida

- Depresión y suicidio

Salud sexual y salud reproductiva

- Salud sexual y salud reproductiva del adolescente

- Embarazo en adolescentes

- Metodología anticonceptiva

- ITS/VIH/SIDA

- Derechos sexuales y reproductivos

- Violencia de género

- Diversidad sexual

\section{METODOLOGÍA:}

Aplicación de técnicas participativas y vivenciales que permiten la reflexión personal y la retroalimentación entre el grupo.

TALLER SOBRE INFECCIONES DE TRANSMISIÓN SEXUAL, VIH Y SIDA

\section{OBJETIVO:}

- Reconocer las prácticas de riesgo que llevan a las personas a adquirir una infección de transmisión sexual, incluido el VIH/SIDA, así como las principales características y las medidas de prevención de las mismas.

\section{DURACIÓN:}

15 horas 


\section{TEMAS:}

- Conceptos básicos de sexualidad

- Diferencia entre una persona travesti, transexual y transgénero

- Derechos humanos, sexuales y reproductivos

- Definición de Infecciones de Transmisión Sexual

- Principales síntomas de las ITS

- ¿Cómo saber si se tiene una ITS?

- Definición de VIH

- Definición de SIDA

- Formas de transmisión del VIH

- Pruebas para detectar el VIH

- Estigma y discriminación que afecta a las personas que viven con el VIH/SIDA

- Prevención del VIH y otras ITS después de una violación sexual

- Prevención del VIH/SIDA, y otras ITS

\section{METODOLOGÍA:}

Este taller se lleva a cabo a partir de una metodología llamada "Educación de la Sexualidad a través de los Cuentos", que se basa en la estrategia de investigación, acción y participación. Esta metodología concede mucha importancia a las necesidades de aprendizaje de las y los participantes, por lo que las sesiones se efectúan en forma de taller para favorecer la intervención activa de los asistentes. Se utiliza el cuento o la narración como el elemento principal del proceso de enseñanza-aprendizaje, ya que a través del análisis y discusión de los cuentos se logra la construcción colectiva de los aprendizajes.

\section{TALLER SOBRE ORIENTACIÓN-CONSEJERÍA}

\section{OBJETIVO:}

- Identificar los principios, las técnicas y los momentos de la consejería.

\section{DURACIÓN:}

6 horas 


\section{TEMAS:}

- Definición de orientación-consejería y sus principios

- Diferencias entre educación, orientación-consejería y terapia

- Perfil del consejero

- Etapas de la orientación-consejería

- Técnicas de la orientación-consejería

\section{METODOLOGÍA:}

Trabajo teórico y práctico sobre aspectos básicos de la orientación-consejería. La metodología que se utiliza para el desarrollo de este taller pone especial énfasis en el desarrollo de las habilidades de comunicación necesarias para llevar a cabo sesiones de orientaciónconsejería.

\section{DIPLOMADO EN SEXUALIDAD HUMANA}

Los diplomados en sexualidad humana consisten en una capacitación especializada en el área de la sexualidad, que puede tener una duración de 8 meses a un año. Se tramitan con las universidades especialistas en el tema, y se abordan tópicos como derechos sexuales y reproductivos; sexualidad humana; metodología anticonceptiva, entre otros. 


\section{RECURSOS DEL PROGRAMA}




\section{RECURSOS MATERIALES}

Para la operación de todo programa juvenil se recomienda contar con diferentes recursos que contribuyan a un adecuado funcionamiento. Éstos son: A) Espacios juveniles y de trabajo; B) Instrumentos de trabajo; C) Materiales educativos, y D) Recursos de operación local.

\section{A) Espacios juveniles y de trabajo}

Si bien las actividades se realizan en diferentes lugares de la comunidad, tales como escuelas, centros de trabajo, clubes deportivos, centros recreativos y de salud, la calle, entre otros, existe una serie de espacios de apoyo que se describirán a continuación. En todos los casos se debe de buscar la oportunidad para que los promotores juveniles y demás colaboradores del programa participen en la decoración y habilitación de los espacios juveniles, de tal manera que sean atractivos para jóvenes y adolescentes. Asimismo, todos los lugares donde se ofrece algún servicio a jóvenes y adolescentes deben estar convenientemente señalizados para que se puedan localizar fácilmente.

- Espacio para jóvenes. En las áreas de trabajo es importante que exista un espacio juvenil amigable y para las personas que colaboran en el Programa y las que están interesadas en participar. Un lugar muy favorable es la clínica propia de la institución, donde la mayoría de las veces existe la infraestructura de apoyo indispensable: almacén, archivo, teléfono, fax, conexión a Internet, cuenta bancaria y lugar para reuniones. Si no existen estas condiciones, el programa de jóvenes puede rentar o conseguir prestado con el municipio o delegación local o estatal, un espacio que ofrezca las características necesarias para servir de punto de referencia: espacios amplios, amigables y decorados de forma creativa por los mismos jóvenes; amplio surtido de métodos anticonceptivos, en especial de condones, anticoncepción de emergencia y material de condonería; materiales educativos; un reproductor de discos compactos, y elementos de señalización claros para llegar al espacio para jóvenes.

- Espacios en instituciones públicas o privadas. En ciertas instituciones que colaboran con el proyecto también se pueden establecer sitios para jóvenes en los que se implementen las actividades del programa. Deben contar con espacios de recreación, intercambio de opiniones y para orientación-consejería, así como con materiales educativos. Se trata de un espacio amigable y original creado por las personas jóvenes para las personas jóvenes.

- Servicios médicos amigables. En todas las clínicas, los consultorios comunitarios amigables para jóvenes y los centros de salud de instituciones que colaboran con el programa, se promueve el establecimiento de servicios amigables de salud sexual juvenil, con 
personal capacitado para atender con calidad y eficiencia a la gente joven que acuda a ellos.

- Farmacias amigas. El programa debe promover en cada área de trabajo la existencia de farmacias amigas, con personal capacitado para atender a jóvenes y adolescentes de manera amable y eficiente.

\section{B) Instrumentos de trabajo}

En áreas de trabajo del programa:

- Proyector de transparencias y, de ser posible, cañón

- Reproductor de DVD o videos VHS

- Reproductora de discos compactos (CD)

- Televisor

- Computadora

Se recomienda disponer de un abasto suficiente de métodos anticonceptivos:

- Condones masculinos

- Condones con aroma, textura, color, sabor

- Condones femeninos

- Pastillas anticonceptivas

- Anticoncepción de emergencia

- Inyecciones anticonceptivas

- DIUs para nulíparas

- Parches anticonceptivos

En consultorios que ofrecen servicios amigables de salud sexual y reproductiva:

- Espejos vaginales pequeños

- Orquidómetro de Prader

- Báscula con estadímetro

- Tablas de crecimiento y desarrollo 
En clínicas para jóvenes:

- Espacio exclusivo de servicios médicos para jóvenes

- Sala de espera amplia, con televisión, reproductor de videos VHS o DVD, revistas y juegos

- Sala de capacitación y reuniones juveniles, con un área de autoaprendizaje

- Cafetería con servicio de Internet y juegos de mesa

- Consultorios numerados y por especialidad

- Oficina del programa juvenil para reunión de promotores juveniles

- Espacio para orientación-consejería

- Laboratorio de análisis clínicos

- Espacio de noticias y anuncios de actividades

- Módulo para venta de materiales educativos y anticonceptivos

- Venta de artículos de interés juvenil que se consiguen en una condonería

- Línea de atención telefónica, a través de la cual se pueda proporcionar información sobre las actividades del Programa y sobre anticoncepción de emergencia

- Carteles de temas referentes a la salud sexual y reproductiva, derechos sexuales y reproductivos de la organización o de otras organizaciones aliadas

- Condones y anticonceptivos, que generalmente se entregan con una cuota de recuperación.

Cabe aclarar que lo antes mencionado es lo que idealmente se necesita, pero es posible aprovechar la propia infraestructura del centro de salud y adecuarla a los requerimientos del Programa.

\section{C) Materiales educativos}

Se recomienda que los materiales educativos que se usen en el programa para gente joven cumplan con las siguientes características:

- Satisfacer las necesidades e intereses de los jóvenes y contemplar su proceso y su momento histórico.

- Contar con metodologías participativas de trabajo con horarios adecuados a los tiempos de la gente joven. 
- Manejar un lenguaje que incluya la perspectiva de equidad de género, la no discriminación y la diversidad sexual.

- Aportar contenidos e imágenes lúdicos, que abarquen distintos temas.

- Ofrecer la información en diferentes formatos (historietas, postales, carteles, cápsulas de radio, cuentos, entre otros).

- Informar a los jóvenes de las diferentes ligas a páginas de Internet exclusivas para ellos.

Es importante revisar, abastecer y cambiar el material educativo que esté caduco por uno actualizado. Todo programa juvenil debe garantizar un abasto permanente de materiales educativos actualizados, así como de condones, anticoncepción de emergencia y anticonceptivos que no estén próximos a caducar, para lo que se recomienda llevar un control de inventarios de almacén.

Se puede consultar un amplio catálogo de materiales y adquirirlos en la siguiente página de Internet: www.mexfam.org.mx.

\section{D) Recursos de operación local}

Apoyo de transporte colectivo al coordinador y a promotores juveniles. Se cubre este gasto para el adecuado desarrollo de las actividades, considerando la distancia y recorrido realizado por día.

Transporte propio de la institución. En caso de que la institución cuente con algún vehículo de transporte, sea bicicleta, motocicleta o automóvil, se recomienda que su uso sea prioritario para las actividades del programa de jóvenes.

\section{RECURSOS FINANCIEROS}

Lograr el sostenimiento de cualquier programa dirigido a la población juvenil representa un enorme reto, en especial cuando se trata de ofrecer educación sexual y servicios de salud sexual y reproductiva. A continuación se exponen algunas iniciativas que contribuyen al sostenimiento financiero de estos programas.

\section{Clínicas de servicios especializados para adolescentes y jóvenes}

Estas clínicas han probado ser autosostenibles; incluso, generan frecuentemente un excedente que permite cubrir los gastos operativos del Programa juvenil. Sin embargo, es importante mencionar que los servicios proporcionados a los jóvenes no son los que generan el sostenimiento ni la rentabilidad. La información financiera y programática revela que los servicios que contribuyen de manera determinante al sostenimiento son los que se brindan a la población adulta. Por ello, es recomendable posicionar este espacio como una clínica 
de jóvenes -lo cual facilitará que sea la población que más solicite los servicios-, pero también es necesario ofrecer servicios al público en general.

\section{Apoyo gubernamental}

Un recurso relativamente exitoso es la transferencia del Programa a las autoridades locales. Es relativamente exitoso porque su permanencia dependerá de la voluntad política de cada lugar y de cada periodo de gobierno, por lo que su situación es vulnerable.

En ocasiones los gobiernos locales (municipios) adoptan y asumen el total del costo del Programa, pero tras los cambios de administración, se pierde el interés -sobre todo cuando gobiernan grupos conservadores-, propiciando el cierre o la mínima operación del Programa.

No obstante, un programa que deja huella logra reactivarse cuando se presentan ciertas oportunidades locales, como la llegada de gobiernos interesados en invertir y trabajar con los jóvenes.

\section{Unión de voluntades}

Sin duda, una estrategia sumamente benéfica es conjuntar el apoyo del gobierno local y de instituciones de la sociedad civil organizada, además de la contribución directa que los usuarios hacen con el pago de cuotas de recuperación por la venta de algún servicio de salud o educativo.

\section{Actividades del Programa para recuperación de gastos}

Existen ciertas actividades que pueden generar recursos financieros. Aunque su contribución es muy importante, su implementación no produce por sí sola los recursos suficientes para financiar la operación de un programa de educación sexual y servicios de salud sexual y reproductiva dirigidos a jóvenes y adolescentes.

Entre las actividades que pueden realizarse están:

- Establecimiento de condonerías

- Venta de programas de capacitación

- Venta de materiales educativos

- Venta de servicios de salud sexual y reproductiva en paquete a escuelas, centros deportivos, centros de trabajo y otros. 


\section{RECURSOS DEL_PROGRAMA}

\section{Capacitación del personal como recaudadores de fondos}

Una opción más consiste en capacitar a los promotores juveniles como recaudadores o generadores de recursos financieros a nivel local para la operación del Programa. Esta propuesta podría resultar poco factible para algunos sectores; sin embargo, existen grupos a nivel mundial -como la Asociación Scout o la YMCA (Young Men's Christian Association)que han desarrollado diferentes formas de generar y recaudar fondos apoyados en su fortaleza juvenil. 


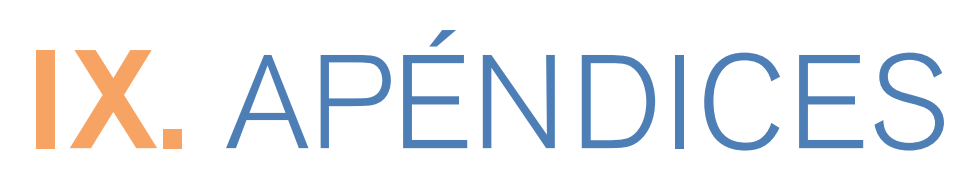

90 


\section{APÉNDICE 1}

\section{CUESTIONARIO DE UBICACIÓN DE LUGARES DE REUNIÓN Y ATENCIÓN A JÓVENES, DIRIGIDO A AUTORIDADES LOCALES Y PERSONAS CLAVES DE LA COMUNIDAD}

\section{(PREVIO A LA IMPLEMENTACIÓN DE UN PROGRAMA)}

El presente cuestionario se aplica a funcionarios públicos y líderes de la comunidad y tiene la finalidad de recopilar información clave relacionada con la población juvenil que habita en el área de influencia en donde se llevará a cabo el programa, así como de todos los servicios que existen, por ejemplo, centros de salud, consultorios médicos, escuelas, farmacias y otros.

Su aplicación tiene formato de entrevista con el fin de obtener la mayor información posible. Toda la información recopilada permitirá contar con elementos más claros y desarrollar un mapeo comunitario para una óptima implementación de las estrategias del programa juvenil.

\section{Datos del entrevistado}

Nombre de la persona que responde el cuestionario:

Cargo que desempeña en la comunidad:

Tiempo de residencia en la comunidad:

\section{Datos de la comunidad}

Nombre de la comunidad/colonia/ barrio:

Número de habitantes: 


\section{Datos estadísticos}

1. ¿Cuántos jóvenes entre 10 y 20 años hay en su comunidad?

2. ¿En qué porcentaje, de esa población de jóvenes, son hombres y mujeres?

3. ¿Cuántas escuelas primarias existen?

4. ¿Cuántas escuelas secundarias o técnicas se ubican en esta zona?

5. ¿Cuántas escuelas preparatorias o técnicas profesionales y de educación superior?

6. ¿Cuántos centros de salud? Favor de especificar si son del IMSS, ISSSTE, SSA, privado u otro.

7. ¿Cuántos consultorios médicos privados hay?

8. ¿Cuántas farmacias?

9. ¿Cuántos centros deportivos?

10. ¿Cuántos centros de esparcimiento cultural para los jóvenes?

11. ¿Cuántas organizaciones del gobierno o de la sociedad civil conoce que están implementando algún programa dirigido a jóvenes?

12. En su opinión, ¿¿cuáles son los problemas que más afectan a los jóvenes de esta comunidad? 


\section{APÉNDICE 2}

SONDEO SOBRE ASPECTOS RELACIONADOS A LA SALUD SEXUAL Y REPRODUCTIVA DE LA GENTE JOVEN, DIRIGIDO A DIRECTORES DE ESCUELAS DE LA ZONA A LAS QUE ASISTEN JÓVENES ENTRE 10 Y 19 AÑOS

\section{(PREVIO A LA IMPLEMENTACIÓN DE UN PROGRAMA)}

El presente cuestionario tiene la finalidad de sondear las posibilidades de trabajo en las escuelas localizadas en el área de influencia del programa juvenil.

Su formato es de auto-aplicación con el fin de recuperar la mayor información posible para el desarrollo y adaptación de las estrategias de trabajo en escuelas.

\section{Datos generales}

Nombre de la persona que responde el cuestionario:

Cargo que desempeña en la escuela:

Nombre de la escuela:

Dirección del plantel:

Tipo de escuela:
o Pública
o Privada
o Otra:

Turnos que maneja:
o Matutino
o Vespertino
o Nocturno

Escuela:
o Primaria
o Secundaria
o Media superior
o Universidad
o Técnicas
o Otra 
No. de estudiantes:

Rango de edad de los estudiantes:

\section{Datos especificos}

1. ¿En qué porcentaje, de esa población de jóvenes, son hombres y mujeres?

2. ¿Cuántos docentes colaboran en esta escuela?

3. ¿Cuántas organizaciones del gobierno o de la sociedad civil conoce que están implementando algún programa dirigido a jóvenes?

4. ¿Alguna de esas organizaciones está realizando algún programa con jóvenes en este plantel? ¿Cuál?

5. En su opinión, ¿̇uáles son los problemas de salud que más afectan a los jóvenes de esta escuela?

6. ¿Ha oído hablar alguna vez de los Derechos Sexuales y Reproductivos que tienen las personas, en especial los jóvenes?
1. Sí
2. No

7. Mencione 3 Derechos Sexuales y Reproductivos que tienen los jóvenes:

1.

2.

3.

8. ¿Qué tan importante cree usted que sería la capacitación del personal docente sobre aspectos relacionados a la salud sexual y reproductiva de los alumnos?
1. Muy importante
2. Importante
3. Poco importante
4. Nada importante

9. ¿Qué tan importante cree usted que sería el trabajo educativo con padres y madres de familia sobre aspectos relacionados a la salud sexual y reproductiva de sus hijos?
1. Muy importante
2. Importante
3. Poco importante
4. Nada importante

10. ¿Usted estaría dispuesto a recibir capacitación y más información sobre temas de salud sexual y reproductiva de los adolescentes y jóvenes?
1. Sí
2. No

\section{Observaciones}




\section{APÉNDICE 3}

\section{CUESTIONARIO SOBRE LA SITUACIÓN DE LOS SERVICIOS DE SALUD SEXUAL Y REPRODUCTIVA DIRIGIDO A DIRECTORES DE CLÍNICAS, CENTROS DE SALUD, HOSPITALES Y MÉDICOS PARTICULARES}

\section{(PREVIO A LA IMPLEMENTACIÓN DE UN PROGRAMA)}

El presente cuestionario tiene el objetivo de recabar la información relacionada con los servicios de salud sexual y reproductiva dirigidos a la población juvenil de entre 10 y 24 años.

1. ¿Cuántos centros o unidades de salud existen en su comunidad?

2. ¿Qué tipo de instituciones proporcionan servicios de salud sexual y reproductiva a los jóvenes y adolescentes?

3. ¿Cuál es el problema de salud que más afecta a los jóvenes y adolescentes de esta comunidad?

4. ¿Existe en su comunidad personal de salud capacitado para atender los problemas específicos de los jóvenes y adolescentes?

5. ¿Existen dentro de los centros de salud o unidades médicas espacios específicos para atender a los jóvenes y adolescentes?

6. ¿Existen programas de salud dirigidos a los jóvenes y adolescentes?

7. ¿Existe demanda de parte de los jóvenes y adolescentes por recibir servicios de salud sexual y reproductiva?

8. No. de privadas No. de públicas De la sociedad civil 


\section{APÉNDICE 4}

\section{CUESTIONARIO DIRIGIDO A FARMACEUTAS Y/O EMPLEADOS DE ATENCIÓN EN MOSTRADOR DE LAS FARMACIAS, PARA CONOCER PERCEPCIONES RESPECTO A LA SALUD SEXUAL Y REPRODUC- TIVA DE LAS Y LOS ADOLESCENTES Y JÓVENES}

\section{(PREVIO A LA IMPLEMENTACIÓN DE UN PROGRAMA)}

El presente cuestionario tiene el objetivo de recabar la información relacionada con el acceso a métodos anticonceptivos, en especial condones, que tienen las y los adolescentes y jóvenes a través de las farmacias ubicadas en el área de influencia del programa.

\section{INSTRUCCIONES: LEA CUIDADOSAMENTE CADA PREGUNTA Y ANOTE EN EL RENGLÓN LO QUE SE PIDE O MARQUE LOS NÚMEROS DE SU RESPUESTA.}

Nombre de la farmacia:

Dirección:

Nombre del farmaceuta responsable:

Nombre de la persona que atiende en mostrador :

Edad (años cumplidos):

Este cuestionario se aplica a las personas que atienden en mostrador.

1. Sexo: $\quad$ Mujer Hombre

2. ¿Cuánto tiempo tiene trabajando atendiendo en la farmacia?

3. ¿Venden métodos anticonceptivos en esta farmacia? Sí No

En caso de ser $\overline{\text { No, ¿ipor qué? }}$

4. ¿Venden métodos anticonceptivos a todas las personas que los solicitan, incluyendo a jóvenes y adolescentes? 
5. ¿Usted ha recibido alguna capacitación relacionada con la prescripción de métodos anticonceptivos?
1. Sí
2. No

6. ¿Considera que la venta de métodos anticonceptivos es importante para esta farmacia?
1. Sí
2. No

7. ¿Usted cree que los condones son un método adecuado para las mujeres adolescentes entre 12-19 años de edad?
1. Sí
2. No

8. ¿Usted cree que los condones son un método adecuado para los hombres adolescentes entre 12-19 años de edad?
1. Sí
2. No

9. ¿Ha oído hablar de las Pastillas de Anticoncepción de Emergencia?
1. Sí
2. No

10. ¿La anticoncepción de emergencia puede ser usada por las mujeres jóvenes y adolescentes?
1. Sí
2. No

11. ¿Usted está de acuerdo en que a los jóvenes y adolescentes se les vendan métodos anticonceptivos sin receta y sin autorización de sus padres o de algún adulto?
1. Sí
2. No
¿Por qué?

12. En su percepción, ¿qué lugar prefieren los adolescentes para obtener métodos anticonceptivos? SELECCIONE SOLO UNA OPCIÓN
1. Farmacia
2. Clínica de gobierno
3. Clínica privada
4. Ninguna de las tres
5. Cualquiera

13. ¿En esta farmacia existe interés por dar atención a adolescentes y jóvenes?
1. Sí
2. No
¿Por qué?

14. En caso afirmativo, ¿qué podría hacer en esta farmacia para que los adolescentes acudieran con más confianza a solicitar información y métodos anticonceptivos? 
15. ¿Qué tan frecuente es que un (a) adolescente le pida información sobre métodos para evitar un embarazo o una Infección de Transmisión Sexual?
1. Muy frecuente
2. Frecuente
3. Poco frecuente
4. Nunca

16. Tomando en cuenta el tipo de información que le piden los adolescentes, ¿qué tan interesado estaría usted en recibir capacitación o más información sobre salud sexual y reproductiva?
1. Muy interesado
2. Interesado
3. Indiferente
4. Nada interesado

17. ¿Qué tan importante cree usted que sería el disponer de folletos informativos sobre salud sexual y reproductiva para entregarlos a los adolescentes en esta farmacia?
1. Muy importante
2. Importante
3. Poco importante
4. Nada importante

18. ¿Usted estaría dispuesto a poner información visible (carteles, rotafolios, etc.) sobre temas de sexualidad en la farmacia?
1. Sí
2. No 


\section{APÉNDICE 5}

\section{FORMULARIO PARA LA EVALUACIÓN CUANTITATIVA DEL BAÚL DE AUTO-APRENDIZAJE EN SALUD SEXUAL Y REPRODUCTIVA}

Núm. de cuestionario [ ]

Nombre del baúl

Fecha:

Hora de llegada:

Hora de salida:

Nombre:

Sexo: $F[$ ] $M[$ ]

Edad:

Ocupación:

Material consultado:

¿Qué es lo que más te interesa saber?

¿Qué es lo que más te gustó y por qué?

¿Alguna pregunta o duda?

¿Crees que falta algún material o información?

¿Cómo te enteraste de este espacio? 


\section{APÉNDICE 6}

\section{FORMULARIO PARA LA EVALUACIÓN CUALITATIVA DEL BAÚL DE AUTO-APRENDIZAJE EN SALUD SEXUAL Y REPRODUCTIVA}

Nombre del baúl:

Fecha:

Edad:

Sexo: Ocupación:

1. ¿Qué te pareció el baúl?

2. ¿Hizo que te interesara explorarlo? ¿Por qué?

3. ¿Aprendiste algo nuevo?

¿En qué temas?

¿Qué temas te gustaron?

¿Qué temas ya conocías?

¿Qué temas te gustaría explorar?

4. ¿Qué sugieres para mejorar el baúl?

5. ¿Te gustaría participar en la construcción de un baúl? 


\section{APÉNDICE 7}

\section{MATERIALES EDUCATIVOS DISPONIBLES EN MEXFAM}

Respecto a los materiales educativos, el Programa Gente Joven ha contribuido en la producción de una diversidad de materiales con la participación de jóvenes, hombres y mujeres menores de 25 años, quienes han colaborado en la planeación, elaboración y evaluación de los mismos. A continuación se presenta un listado de los materiales básicos para el desarrollo de las actividades de información, educación y comunicación del Programa.

\section{Laminógrafos:}

- Pubertad y proceso reproductivo

\section{Videos:}

- Sueño o realidad

- La paloma azul

- El último tren

- Saxofón

- Con las manos en los bolsillos

- Como cuates

- Música para dos

- Los mejores deseos

- En fuga

- Esto es cosa de hombres, ¿̇o de mujeres?

- Compás de espera

- No existen diferencias

- La historia de Mariana

- Anticoncepción de emergencia

- La vida de Juan (producida por Promundo)

- Salud sexual juvenil: estrategias exitosas para gente joven en América Latina y el Caribe

\section{Diaporamas:}

- Lo que necesitamos saber sobre VIH/SIDA

\section{Libros:}

- Hablemos de sexualidades con la gente joven 


\section{Folletos:}

- Pubertad y menstruación

- ITS

- VIH/SIDA

- Métodos anticonceptivos

- Anticoncepción de emergencia

- Todas y todos tenemos derechos

- Todos somos diferentes

- La primera vez

- Si ya estás harto o harta

- Acordeón de condón masculino y femenino

\section{Postales:}

- Postales de la diversidad

- De anticoncepción de emergencia

\section{Encartes:}

- MEXFAM, A.C.

- Programa Gente Joven

- Farmacias amigas

- Un prestador amigable

\section{Carteles:}

- Salud sexual

- Los niños son maravillosos

- Si te prendiste demasiado

- No sea pene

- Ya!! (uso de condón)

- Ábrete a la sexualidad

- Anticoncepción de emergencia

- Cartel sobre diversidad sexual

\section{Audio:}

- La serie de Conodos sobre derechos sexuales de la población LGTB

\section{2}


La Fundación Mexicana para la Planeación Familiar, A.C., es una asociación civil sin fines de lucro, gobernada por voluntarios y dirigida por un selecto grupo de profesionistas, empresarios, políticos, artistas e intelectuales. Se fundó en 1965 y es miembro de la Federación Internacional de Planificación de la Familia/Región del Hemisferio Occidental (IPPF/RHO). La misión de MEXFAM es la de proporcionar servicios de calidad y de vanguardia en planeación familiar, salud y educación sexual, dando atención prioritaria a la población vulnerable de México: los jóvenes y los pobres.

Fundación Mexicana para la Planeación Familiar, A.C.

Juárez 209, Tlalpan, México, D. F.

Tel. 0152 (55) 5487-0030

www.gentejoven.org.mx o www.mexfam.org.mx 